\title{
Economic feasibility of ultra-low temperature district heating systems in newly built areas supplied by renewable energy
}

Meesenburg, Wiebke; Ommen, Torben; Thorsen, Jan Eric; Elmegaard, Brian

Published in:

Energy

Link to article, DOI:

10.1016/j.energy.2019.116496

Publication date:

2020

Document Version

Peer reviewed version

Link back to DTU Orbit

Citation (APA):

Meesenburg, W., Ommen, T., Thorsen, J. E., \& Elmegaard, B. (2020). Economic feasibility of ultra-low temperature district heating systems in newly built areas supplied by renewable energy. Energy, 191, [116496]. https://doi.org/10.1016/j.energy.2019.116496

\section{General rights}

Copyright and moral rights for the publications made accessible in the public portal are retained by the authors and/or other copyright owners and it is a condition of accessing publications that users recognise and abide by the legal requirements associated with these rights.

- Users may download and print one copy of any publication from the public portal for the purpose of private study or research.

- You may not further distribute the material or use it for any profit-making activity or commercial gain

- You may freely distribute the URL identifying the publication in the public portal 


\section{Journal Pre-proof}

Economic feasibility of ultra-low temperature district heating systems in newly built areas supplied by renewable energy

Wiebke Meesenburg, Torben Ommen, Jan Eric Thorsen, Brian Elmegaard

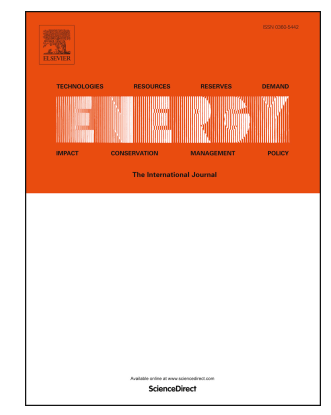

PII: $\quad$ S0360-5442(19)32191-7

DOI: $\quad$ https://doi.org/10.1016/j.energy.2019.116496

Reference: EGY 116496

To appear in: Energy

Received Date: 29 April 2019

Revised Date: 27 October 2019

Accepted Date: 5 November 2019

Please cite this article as: Meesenburg W, Ommen T, Thorsen JE, Elmegaard B, Economic feasibility of ultra-low temperature district heating systems in newly built areas supplied by renewable energy, Energy (2019), doi: https://doi.org/10.1016/j.energy.2019.116496.

This is a PDF file of an article that has undergone enhancements after acceptance, such as the addition of a cover page and metadata, and formatting for readability, but it is not yet the definitive version of record. This version will undergo additional copyediting, typesetting and review before it is published in its final form, but we are providing this version to give early visibility of the article. Please note that, during the production process, errors may be discovered which could affect the content, and all legal disclaimers that apply to the journal pertain.

(C) 2019 Published by Elsevier Ltd. 


\title{
Economic feasibility of ultra-low temperature district heating systems in newly built areas supplied by renewable energy
}

Wiebke Meesenburg ${ }^{1}$, Torben Ommen ${ }^{1}$, Jan Eric Thorsen ${ }^{2}$, Brian Elmegaard ${ }^{1}$

${ }^{1}$ Technical University of Denmark, Department of Mechanical Engineering, Niels Koppels Allé 403, DK2800 Kgs. Lyngby

2 Danfoss A/S, Nordborgvej 81, DK-6430 Nordborg

\begin{abstract}
Future district heating systems are expected to supply lower temperatures to increase system efficiency and enable exploitation of renewable heat sources. To answer whether it is beneficial to lower district heating temperatures below the level where it is still possible to supply domestic hot water directly, the economic feasibility of three ultra-low temperature district heating (ULTDH) concepts was compared to low temperature district heating (LTDH). The dependency of the economic feasibility on the boundary conditions of the supplied district heating area was assessed systematically and feasible boundary conditions were identified. For this purpose building plot ratio, specific heat demand and central heating unit were varied. The different solutions were compared based on levelised cost of heat, socioeconomic net present value and overall seasonal coefficient of performance. It was found that in most cases LTDH was economically preferred. ULTDH could be feasible if the linear heat demand density (LHDD) was high, if the cost of decentral units could be lowered or if the investment cost of the central heating unit was significantly lower compared to LTDH. Among the ULTDH solutions, apartment units were preferable for low LHDD, while units at building level performed better for larger LHDD.
\end{abstract}

\section{Nomenclature}

\begin{tabular}{|c|c|c|c|c|}
\hline \multicolumn{2}{|c|}{ Abbreviations } & \multirow{2}{*}{$\begin{array}{l}q \\
q_{l}\end{array}$} & \multirow{2}{*}{$\begin{array}{l}\text { Specific heat demand } \\
\text { Linear heat demand } \\
\text { density }\end{array}$} & \multirow{2}{*}{$\begin{array}{l}k W h / m^{2} / a \\
M W h / m \\
/ a\end{array}$} \\
\hline $\mathrm{CHP}$ & Combined heat and power & & & \\
\hline COP & Coefficient of performance & $s_{\mathrm{SH}}$ & Space heating share & - \\
\hline DH & District heating & $T$ & Temperature & ${ }^{\circ} \mathrm{C}$ \\
\hline DHW & Domestic hot water & $\bar{T}$ & Average temperature & ${ }^{\circ} \mathrm{C}$ \\
\hline HEX & Heat exchanger & $t$ & Time & $h$ \\
\hline $\mathrm{HP}$ & Heat pump & $\dot{V}$ & Volume flow & $m^{3} / h$ \\
\hline $\mathrm{LCOH}$ & Levelised cost of heat $\quad € / M W h$ & $W$ & Electric energy & $W h$ \\
\hline LTDH & Low temperature district heating & $\dot{W}$ & Power & $W$ \\
\hline NPV & Net present value $\quad €$ & \multicolumn{3}{|c|}{ Greek symbols } \\
\hline O\&M & Operation and maintenance & $\epsilon$ & Plot ratio & - \\
\hline $\mathrm{SH}$ & Space heating & $\rho$ & Density & $\mathrm{kg} / \mathrm{m}^{3}$ \\
\hline ULTDH & Ultra-low temperature district heating & Subscripts & & \\
\hline \multicolumn{2}{|c|}{ Latin symbols } & fixedOM & Fixed $O \& M$ cost & \\
\hline$A$ & Area & forw & DH forward & \\
\hline C & Cost & I & linear & \\
\hline$c_{p}$ & Specific heat capacity & nom & nominal & \\
\hline$L$ & Pipe length & ret & DH return & \\
\hline
\end{tabular}




\begin{tabular}{|llcll|}
\hline$p$ & pressure & $P a$ & $\mathrm{~s}$ & Annual specific \\
$Q$ & Heat & $W h$ & tot & total \\
$\dot{Q}$ & Heat flow & $W$ & & \\
\hline
\end{tabular}

\section{Introduction}

District heating $(\mathrm{DH})$ is expected to play a key role in future renewable and energy efficient energy systems. Such systems are likely characterized by high shares of electricity generation from intermittent renewable energy sources and the need to exploit renewable heat sources. Lund et al. [1] define several criteria that a future $\mathrm{DH}$ grid has to comply with in order to play the expected central role: 1) The ability to supply low-temperature $\mathrm{DH}$ for space heating $(\mathrm{SH})$ and domestic hot water (DHW) preparation, 2) reduction of grid losses, 3) exploitation of renewable and excess heat sources, 4) being an integrated part of the overall energy system and 5) suitable planning and policy instruments. The first three criteria are directly connected to lower $\mathrm{DH}$ temperatures. To enable these, the supplied buildings need to be equipped with $\mathrm{SH}$ and DHW systems that can be supplied with low-temperatures, likely down to $45^{\circ} \mathrm{C}$ to $55^{\circ} \mathrm{C}$. Reduction of system temperatures will increase the distribution efficiency, due to reduced heat losses from the pipes. The integration of renewable and excess heat sources is enhanced by low DH temperatures too, as lower temperature sources can be used. These ambient and low-grade heat sources can be exploited by large-scale heat pumps, which benefit from lower $\mathrm{DH}$ temperatures, as the coefficient of performance (COP) increases for lower temperature lifts. Heat pumps can also help to fulfil the fourth criterion, as they provide a link between the power and heating networks and might be able to balance the power grid by making use of the immanent thermal storage capacity of the DHsystem. Planning and policy instruments are needed in order to shape the system such that the first four criteria may be fulfilled.

\subsection{Low temperature- and ultra-low temperature district heating}

Low temperature district heating denotes district heating with considerably lowered supply and return temperatures compared to conventional district heating. Design supply temperatures can reach down to $55^{\circ} \mathrm{C}$, which still allows direct supply of DHW to the buildings via direct heat exchange. In this case, the $\mathrm{DH}$ forward temperature is constrained by the minimum temperature required to avoid legionella in DHW. Ultra-low temperature district heating (ULTDH) systems are operated at even lower district heating temperatures, that can reach down to around $40^{\circ} \mathrm{C}$ forward temperature. These temperatures are high enough to supply SH directly, but decentral heating units are necessary to increase the DH temperature to supply DHW to the customers. This can be done using decentral heat pumps (HP). The lower DH temperature allows to further reduce grid losses compared to LTDH, as found for a Danish case study by Yang \& Svendsen [2]. However, part of the heat used to provide DHW is replaced by electricity to run the decentral HPs, which results in a reduced exergy utilization as the reduction of heat loss is outweighed by the additional electricity demand of the decentral HP, as shown by Elmegaard et al. [3]. This result is in agreement with the results by Yang \& Svendsen.

Ommen et al. [4] investigated the influence of distribution temperatures on the performance of largescale heat pumps and combined heat and power (CHP) plants as the central heat supply unit. The considered decentral heating unit is a HP using DH water as heat source. The results showed that energy efficiency increases for ULTDH compared to LTDH, if supplied by a central HP, and decreases if supplied by a CHP plant. 


\subsection{Previous work on economic feasibility of ultra-low temperature district heating systems}

The economic profitability of ULTDH and LTDH is challenged as the linear heat demand density (LHDD) is reduced, which generally decreases the profitability of $\mathrm{DH}$ systems [5]. More detailed analysis of the economic performance of ULTDH has been investigated for specific DH systems.

Ommen et al. [6] examined the influence of DH temperatures on the consumer cost in the Greater Copenhagen DH network for supply from CHP only, and for integration of large-scale HPs into the supply portfolio. They show that reducing the $\mathrm{DH}$ temperature to $60^{\circ} \mathrm{C}$ leads to minimal consumer costs. Further reduction in $\mathrm{DH}$ forward temperature results in increasing cost, as boosting of the temperature for DHW becomes necessary.

Yang \& Svendsen [2] conducted a Danish case study of a DH network supplied by a central groundsource heat pump supplemented with CHP and heat only boiler. They find that the operation cost of the system is lower for ULTDH than for LTDH. The heat losses in the LTDH case appear to be high with $25 \%$ to $55 \%$. Best et al. [7] compared the economic feasibility of ULTDH and LTDH for a similar network in Germany, which is supplied by a ground-source HP with a borehole thermal energy storage. The decentral units considered for ULTDH are air-source HPs. The share of SH was $78 \%$ of the overall heat demand, which is defined as SH- plus DHW demand. They found that the higher cost for decentral boosting for DHW preparation is offset by savings in heat distribution cost and central heat generation cost, due to a better COP of the central HP in the ULTDH case.

Vivian et al. [8] analysed the economic feasibility of ULTDH from a customer perspective for a network supplying mainly older buildings in Italy. As the existing buildings have higher temperature demands for $\mathrm{SH}$ than the DH forward temperature, the booster HPs have to provide SH in addition to DHW. They find that the levelised cost of heat in ULTDH systems decreases with increasing DH supply temperatures, indicating that a LTDH solution might be beneficial.

Köfinger et al. [9] studied different low- and ultra-low temperature DH configurations for four cases in Austria. They recommend using booster units in combination with ULTDH when the heat source supply temperature has an upper constraint or when large amounts of DHW have to be stored in the buildings, e.g. in hotels. They emphasize that reduced heat losses and network investment cost prove to be especially beneficial in low heat density areas.

Lund et al. [10] compared the feasibility of ULTDH with LTDH on an energy system level from a societal point of view. They find that LTDH has the lowest socioeconomic cost but that ULTDH with booster heat pump substations may be feasible in specific cases under the right circumstances. $\varnothing$ stergaard \& Andersen [11] compare the operation cost of ULTDH and LTDH. They find that operation cost of ULTDH can be reduced compared to LTDH due to lower energy losses in the network. However, booster HP investment cost were not included in their analysis.

\subsection{Scope of this study}

While most studies point towards LTDH as the more feasible system, some show economically feasible ULTDH systems. All of the above mentioned studies compared different ULTDH and LTDH solutions which were carried out for specific cases. Accordingly, a more systematic analysis of the influence of the different boundary conditions on the feasibility of ULTDH systems is needed to predict which solutions 
should be evaluated for new development areas. Therefore, the present study aimed at identifying how the characteristics of the supplied area and of the heat supply technologies influence the socioeconomic feasibility of heat supply technologies. This can be useful information in the early planning stages for new development areas. By identifying the feasibility of different district heating solutions in the nexus between the boundary conditions imposed by the supplied area and the available heat sources, the study addresses a techno-economic perspective, which is different to existing assessments based on energy system analysis as well as to studies of performance improvements of district heating cascade systems. The aim is to identify the most promising pathways of heat supply to future developments. The results of the studies mentioned above indicate that the feasibility of ULTDH is affected by many parameters, of which key items are listed in the following:

- $\quad \mathrm{SH}$ - and DHW temperature requirements

- Heat demand density of the supplied area

- Share of SH demand of the overall heat demand

- Type of central DH supply unit

- Price of heat supplied by DH and price of electricity

The current study assessed the influence of these parameters on the economic feasibility of ULTDH compared to LTDH, in order to identify under which boundary conditions, one or another of these technologies should be applied. Further, the influence of the booster HP configuration and the corresponding operation and investment cost on the overall systems feasibility was assessed, to account for different possible ULTDH variants. This was done by calculating the levelised cost of heat (LCOH) and the socioeconomic net present value (NPV), including all contributions from heat source to demand, assuming Danish prices and taxes. The analysis was based on a generalized modelling approach for the district heating network to be able to show trends of technology feasibility for networks under significantly different boundary conditions. The method is further described in section 2 as well as the different configurations that were assessed. The results are presented in section 3 , before they are discussed in section 4. Final conclusions are presented in section 5. 


\section{Method}

To assess the economic feasibility of ULTDH systems in Denmark under varying boundary conditions, an economic analysis was conducted using a Microsoft Excel/VBA based tool, based on the district heating assessment tool (DHAT), published by the Danish Energy Agency [12]. A principle sketch of the assessed systems is given in Figure 1. All systems included energy supply in form of power supply, natural gas for the back-up unit and heat sources for the heat pump units. Further, different central energy conversion units were considered, supplying the heat demand via the DH network and transferring it in the customers substation. The whole system's performance and economy were influenced by different physical- and policy boundary conditions, as indicated in Figure 1.

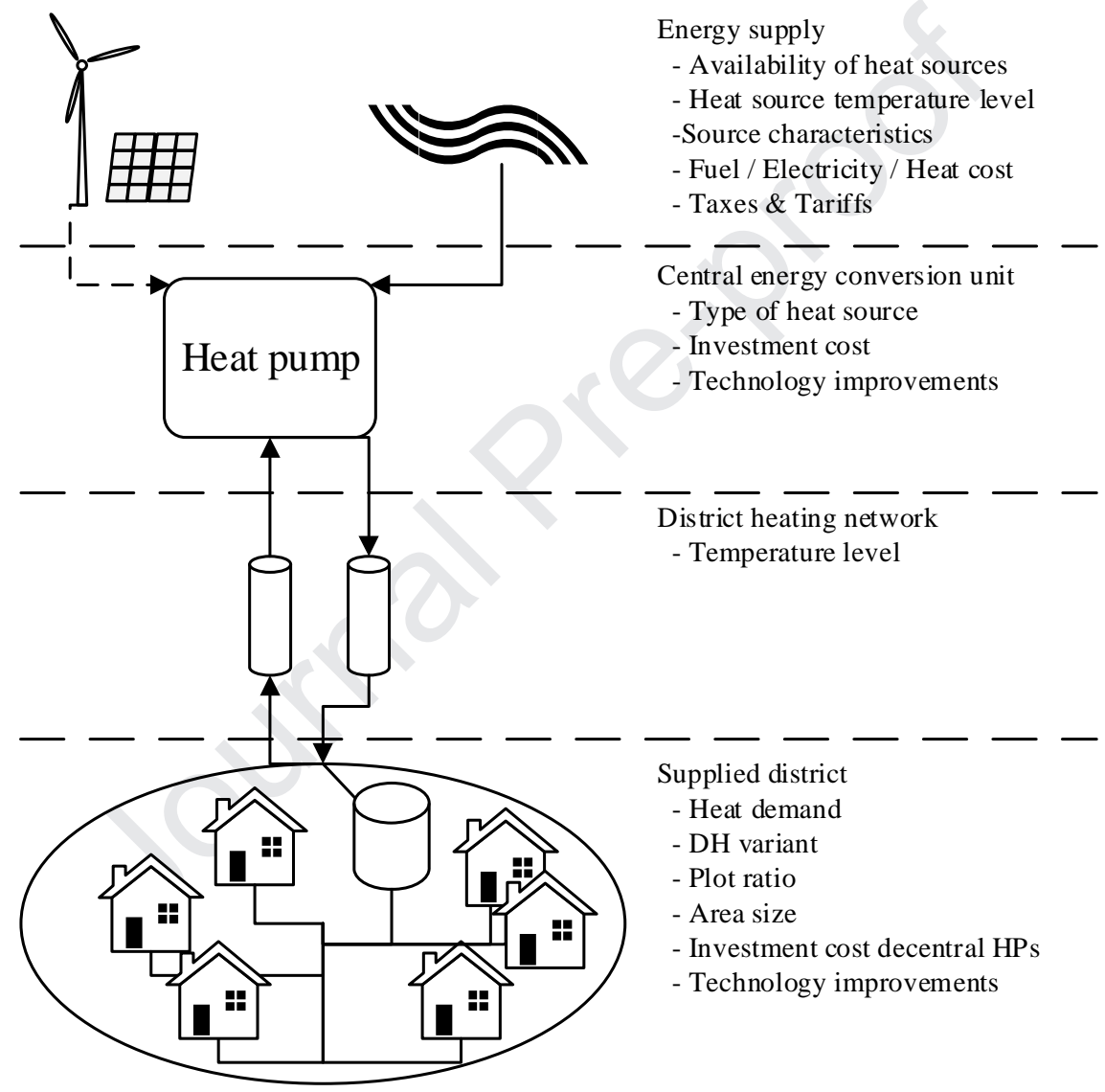

Figure 1 Overview of the system, including four main parts; energy supply, central energy conversion, DH network and supplied district. Varied boundary conditions influencing the different parts of the system are given as bullet points.

\subsection{Assessed system designs}

Three different ULTDH system designs were assessed, and compared to the performance of a LTDH system and to supply by individual air-to-water heat pumps. Figure 2 shows a sketch of the different system design cases.

Case 1), was LTDH with design system temperatures of $60^{\circ} \mathrm{C}$ forward and $30^{\circ} \mathrm{C}$ return. These temperatures specify the temperatures to be supplied to, and returned from, the last customer in the network. For all three ULTDH cases temperatures of $40{ }^{\circ} \mathrm{C}$ forward and $25^{\circ} \mathrm{C}$ return were assumed, 
using the above definition of forward and return. They differed in the type and form of implementation of the decentral HPs. In case 2) "ULTDH-DH" the booster HP was using the DH forward stream as sink and source. Substation and booster HP were implemented at building level. The advantages of this configuration were a high booster HP COP of 5.23 and relatively high LHDDs in the DH network compared to case 3). Case 3) "ULTDH-air" used an air-source HP to supply DHW to the building. The COP was lower compared to case 2, with 2.9 to 3.3. In case 2) and 3) it was assumed that the DHW temperature supplied to the tanks in the building is $60^{\circ} \mathrm{C}$ and the COPs were calculated as described in section 2.2.4. The last case "ULTDH-DH-micro" comprised micro-booster HPs at apartment level. In accordance with supplier data, the DHW temperatures were assumed to be as low as $53.5^{\circ} \mathrm{C}$ and the micro-booster HP achieved an average COP of 6.7 for DH supply temperatures of $40^{\circ} \mathrm{C}$ [13]. In this case, anti-Legionella disinfection was carried out by shortly increasing DHW temperatures once or twice per week. The respective extra HP consumption was given by the manufacturer as $1 \%$ of the calculated power consumption without disinfection [14] and was neglected.

For all cases, weather compensation was applied for outdoor temperatures below $5^{\circ} \mathrm{C}$, increasing the $\mathrm{DH}$ supply temperature by $1 \mathrm{~K}$ for a decrease of $1 \mathrm{~K}$ in outdoor temperature, up to a maximum compensation of $17 \mathrm{~K}$ [2]. The supply temperatures of DHW from the individual DHW HPs was assumed to be unaffected by outdoor temperatures. It was assumed that the heat is transferred from the $\mathrm{DH}$ grid to the building SH and DHW system via an indirect DH substation. It was further assumed that the return temperature from the DH substations can be kept constant throughout the year, which is a simplification as the return temperature would usually vary as the forward temperatures vary. This is further discussed in chapter 4 . In all cases, the circulation losses within the buildings were assumed to be part of the specific heat demand of the buildings. 


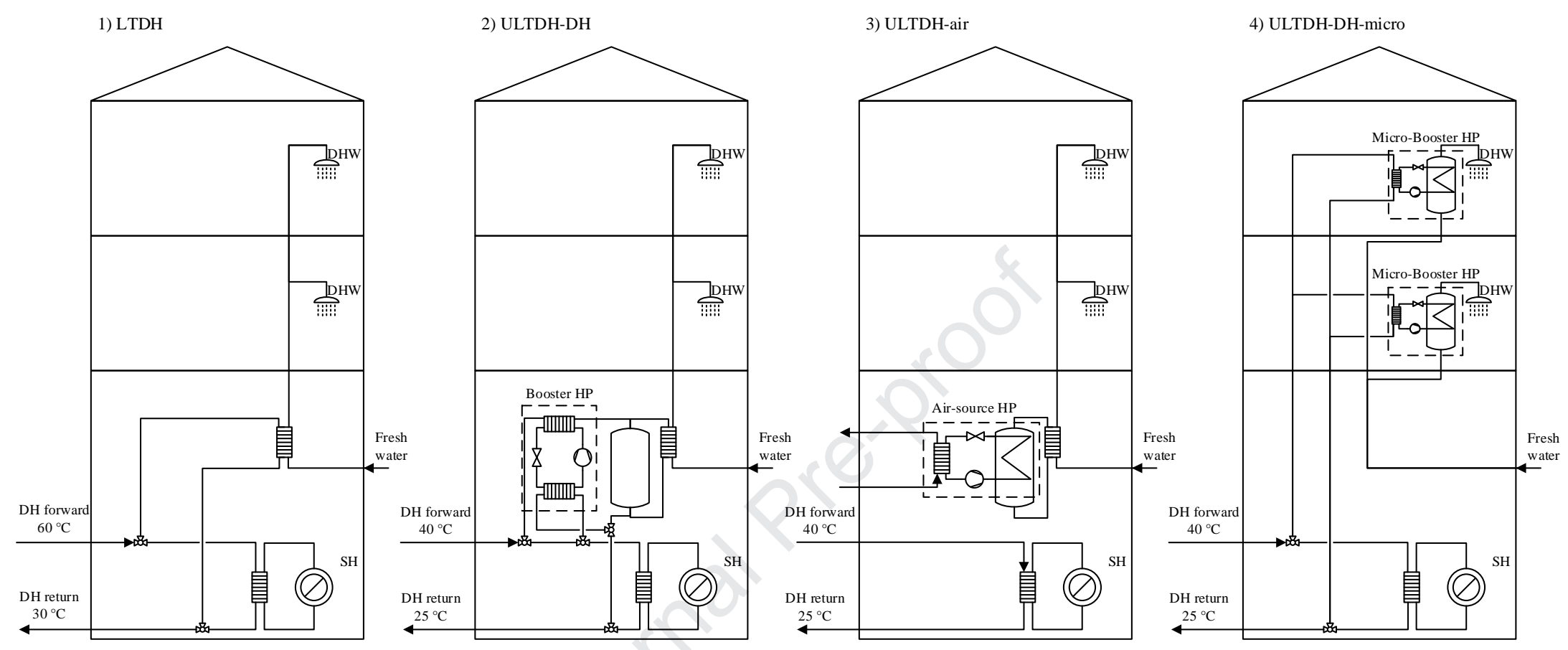

Figure 2 Four system design cases: 1) LTDH with indirect DH substation at building level, 2) ULTDH with water-to-water booster HP at building level, 3) ULTDH with air-to-water HP at building level (the evaporator and compressor unit is usually placed outdoors, but was drawn inside for simplicity), 4) ULTDH with water-to-water booster HP at apartment level, including direct preheating of the fresh water. 


\subsubsection{Heat sources}

Air-source evaporators and ground source systems were considered as natural heat sources. The cost of heat supplied to the evaporator, caused by pump or fan power consumption, was neglected. The sensitivity to this assumption was assessed (see section 3.5). Air-source heat pumps experience frosting at ambient temperatures of around $7{ }^{\circ} \mathrm{C}$ and lower, which leads to a reduction of COP due to defrosting and to a reduction of heating capacity, as frost formation on the evaporator reduces the heat transfer [15]. This effect was considered by reduction factors for COP and heating capacity for outdoor temperatures below $7{ }^{\circ} \mathrm{C}$. The assumed reduction factor for the COP was 0.84 and for the heating capacity 0.85 . These values are mean values of the data presented by Mader [15]. This simplified approach was chosen, as a more detailed modelling of the defrosting was beyond the scope of this study.

Further, excess heat at temperatures of $40{ }^{\circ} \mathrm{C}, 30^{\circ} \mathrm{C}$ and $20^{\circ} \mathrm{C}$, was used as heat source for a central HP. It was assumed that all sources were cooled down to $10^{\circ} \mathrm{C}$ by the HP. Lastly, a case of excess heat at temperatures high enough to supply ULTDH directly at all time was considered as an idealized situation. This was a theoretic case and the heat source was not further specified. In this case the investment cost was reduced to that of a heat exchanger substation.

In principle the excess heat cost is highly dependent on the type of process it originates from and the cost that occurs to make the excess heat available. The type of process was beyond the chosen detail level for this study, and accordingly it was decided to vary the excess heat cost to be $0 € / \mathrm{MWh}$, $10 € / \mathrm{MWh}$ and $20 € / \mathrm{MWh}$, and thereby assess how much the cost influences the overall feasibility, similar to the approach chosen by Bühler et al. [16].

\subsection{Representation of DH system}

To assess under which circumstance ULTDH or LTDH is economically preferable, a generic representation of the DH network and customer structure was developed. Accordingly, no detailed network analysis was conducted, but the calculation of heat demand, DH grid investment, heat loss and pumping power were based on current regulations and estimations from existing DH grids in Denmark and Sweden. The analysis was limited to newly developed, predominantly residential areas and the district area was fixed to $340000 \mathrm{~m}^{2}$, which is the area of the Levantkaj city development area in Copenhagen [17]. To verify that a fixed district area is a feasible assumption the influence of the district area on the result was tested.

The performance of the system was evaluated based on the seasonal system COP, which is defined in line with the definition of the seasonal COP for heat pumps [18]. It was calculated as the total annual heat supplied to the customers $Q_{t o t, d e m a n d}$ divided by the total annual electricity input $W_{t o t}$, which is the sum of the electricity input to the central heating units, decentral heating units and DH pumping power.

$$
\mathrm{COP}_{\text {system,seasonal }}=\frac{Q_{\text {tot,demand }}}{W_{\text {tot }}}=\frac{\int_{\text {year }} \dot{Q}_{\text {tot,demand }} d t}{\int_{\text {year }} \dot{W}_{\text {tot }} d t}
$$




\subsubsection{Estimation of heat demand}

The specific DHW demand $q_{\text {DHW }}$ was assumed to be $20 \mathrm{kWh} / \mathrm{m}^{2} / \mathrm{a}$ [19]. The share of SH of the total heat demand $s_{\mathrm{SH}}$ was varied between 0.1 and 0.8 in steps of 0.1 , representing different building energy efficiencies. The Danish 2020 building standard employs a SH share of 0[20].

$$
s_{\mathrm{SH}}=\frac{Q_{\mathrm{tot}, \mathrm{SH}}}{Q_{\mathrm{tot}, \mathrm{DHW}}+Q_{\mathrm{tot}, \mathrm{SH}}}
$$

The specific annual heat demand $q_{s}$ was calculated from the specific DHW demand and the SH share.

$$
q_{s}=q_{\mathrm{DHW}}+q_{\mathrm{SH}}=\frac{1}{1-s_{\mathrm{SH}}} \cdot q_{\mathrm{DHW}}
$$

The yearly SH demand profile was generated by weighting the heat demand according to the Danish Design Reference Year [21]. The DHW demand was determined by two components: The basic daily demand pattern, which was assumed to be the European standard tapping profile (XL load) [22] and a factor representing the seasonal variations of DHW demand. The seasonal correction factor was dependent on the outdoor temperature and was obtained by normalizing the measurements by Aronsson $[23,24]$ with the corresponding mean temperatures of the same year.

The overall annual heat demand was calculated from the total heated building area. The heated building area $A_{\text {buildings }}$ was calculated from the overall district area $A_{\text {district }}$ and the plot ratio $\epsilon$, which was considered an input for the analysis.

$$
\epsilon=\frac{A_{\text {buildings }}}{A_{\text {district }}} \Leftrightarrow A_{\text {buildings }}=\epsilon \cdot A_{\text {district }}
$$

The plot ratio was varied from 0.2 (rural) to 2 (urban) in steps of 0.2 to account for different building densities.

\subsubsection{Estimation of network investment}

The network investment cost was estimated from plot ratio, expected specific heat demand, effective width and estimated average pipe diameter, following the approach developed by Persson \& Werner [25] and Frederiksen \& Werner [24]. Piping cost were fitted to Danish empirical data [12].

\subsubsection{Estimation of heat loss and pumping power}

The heat loss is an important factor for the feasibility of $\mathrm{DH}$, especially in heat sparse areas. The expectable heat loss from the network was estimated using an empirical approach. Figure 3 shows the heat loss of 187 DH networks in Denmark as a function of their LHDD [26]. It is defined as the total annual heat demand divided by the estimated trench length $L$ and it can be calculated from the annual specific heat demand, the plot ratio and the characteristic width, as described in [25].

$$
q_{l}=\frac{Q_{t o t}}{L}=q_{s} \cdot \epsilon \cdot w
$$

Networks with LHDD above five were excluded. The heat loss was corrected according to forward and return temperatures. As can be seen in Figure 3 the data is spread out, which may be caused by different operation conditions and malfunctions in the systems. A power function was used to fit the 
data. To calculate the relative annual heat loss the correction for the assumed network temperatures for LTDH and ULTDH was applied to the correlation found from this data. The full equation is:

$$
\frac{Q_{\text {loss }}}{Q_{\text {tot }}}=0.2748 \cdot q_{l}^{-0.653} \cdot \frac{T_{\text {forw }}+T_{\text {ret }}-2 \cdot T_{\text {ground }}}{\bar{T}_{\text {forw }}+\bar{T}_{\text {ret }}-2 \cdot T_{\text {ground }}}
$$

$\bar{T}_{\text {forw }}=73.71{ }^{\circ} \mathrm{C}$ and $\bar{T}_{\text {ret }}=40.52^{\circ} \mathrm{C}$ are the weighted average forward and return temperature (by heat load) of the Danish systems listed in the data base.

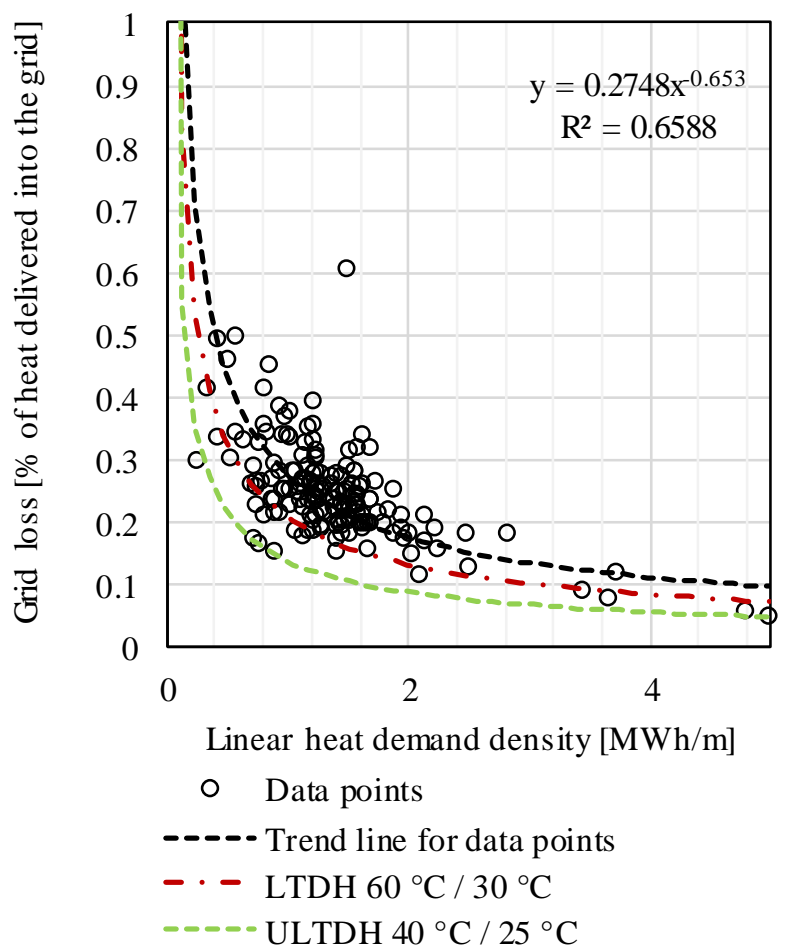

Figure 3 Heat loss data from existing DH networks corrected to average forward and return temperatures in Denmark, 2017, and fitted power function based on data from [26]

The pumping power needed for a system depends on the system design. Any estimation made without knowing the detailed piping layout has large uncertainties. In general, the pumping power can be calculated as the product of the volume flow, the pressure drop and the pump's efficiency. The average volume flow through the primary pumps was estimated from the total heat delivered into the system and the forward and return temperatures at the central unit.

$$
\dot{V}=\frac{\left(\frac{Q_{\text {tot,delivered }}}{8760[h / a]}\right)}{c_{\mathrm{p}, \mathrm{H}_{2} \mathrm{O}} \cdot\left(T_{\text {forw }}-T_{\text {ret }}\right) \cdot \rho_{\mathrm{H}_{2} \mathrm{O}}}
$$

The pressure drop in the system was estimated assuming a constant pressure gradient in all the pipes of $100 \mathrm{~Pa} / \mathrm{m}$ [24]. The corresponding pipe length was set to the estimated trench length L, which was calculated from equation (5), according to [25]. 
The pressure loss over the substations was assumed to be 1 bar [27]. The necessary energy for pumping per year is calculated as:

$$
W_{\text {pump }}=\Delta p_{\mathrm{DH}} \cdot \dot{V} \cdot \eta_{\text {pump }} \cdot 8760\left[\frac{\mathrm{h}}{\mathrm{a}}\right]
$$

Here, $\Delta p_{\mathrm{DH}}$ denotes the overall pressure loss, $\dot{V}$ is the average volume flow and $\eta_{\text {pump }}$ is the isentropic efficiency of the pump, which was assumed to be 0.8 .

\subsubsection{Representation of HP units}

To calculate the seasonal COP of the HPs the Danish Design Reference Year [21] temperature data was used as air-source temperature. The groundwater temperature was assumed to be $10^{\circ} \mathrm{C}$, the excess heat temperature was assumed to be $20^{\circ} \mathrm{C}, 30^{\circ} \mathrm{C}$ and $40^{\circ} \mathrm{C}$, and constant throughout the year. The source temperature for decentral heat pumps was given as the air temperature for the air-source heat pump and as the ULTDH forward temperature for the DH-source booster HP. The coefficient of performance (COP), defined as

$$
\mathrm{COP}=\frac{\dot{\mathrm{Q}}_{\mathrm{HP}}}{\dot{W}_{\mathrm{HP}}}
$$

was estimated from sink- and source temperatures, isentropic efficiency, compressor heat loss factor and the ratio of isentropic expansion- and -compression work, using the method described by Jensen et al. [28]. To determine these parameters, ammonia was assumed as refrigerant for large-scale HPs and isobutane for decentral units. The COP for all HPs was calculated for every hour of the year. Knowing the hourly COP and heat demand, the corresponding electric energy consumption was calculated. The seasonal COP of the HP units could then be calculated equivalent to the system's seasonal COP, (equation (1)).

The capacity of the central heat pump unit was set to be $80 \%$ of the maximum hourly heating demand for LTDH. The backup electricity boiler capacity was $25 \%$ of the maximum heat demand. For the ULTDH cases, the heat capacity of central HPs was set to the maximum DH demand value. For ULTDH-DH and ULTDH-DH-micro, the annual DH demand was calculated as the difference of the total heat demand (including losses) minus the electric energy input to the booster HPs.

$$
Q_{\text {central }}=Q_{\text {supply,tot }}-\frac{\left(1-s_{\mathrm{SH}}\right) \cdot Q_{\mathrm{demand}, \mathrm{tot}}}{\mathrm{COP}_{\mathrm{booster}}}
$$

The heat capacity of the booster HP was constrained to be between $2 \mathrm{~kW}$ and $14 \mathrm{~kW}$, which corresponded to previously demonstrated booster HP capacities (as of December 2018). The capacity of the micro-booster HP was fixed to $1.8 \mathrm{~kW}$ per installation. In the ULTDH-air case, the DH demand was the $\mathrm{SH}$ demand plus distribution losses. The heat supplied by the decentral HPs was the DHW heat demand. The capacity of the decentral units for ULTDH-DH and ULTDH-air was determined assuming a fixed number of full load hours of $2000 \mathrm{~h} / \mathrm{a}$, which is in line with [29] and was tested for sensitivity. 


$$
\dot{Q}_{\text {booster,nom }}=\frac{Q_{\text {DHW }}}{t_{\text {fulload }}}
$$

The air-source HP capacity did not have an upper boundary.

\subsection{Economic evaluation}

The economic feasibility of all assessed $\mathrm{DH}$ configurations was compared based on $\mathrm{LCOH}$ and socioeconomic NPV. Investment cost for central supply units, DH grid incl. local substations, and decentral HPs were considered. Electricity price, and operation and maintenance (O\&M) cost were included in the economic analysis. Taxes were based on Danish regulation as of September 2018.

\subsubsection{Calculation of levelised cost of heat and socioeconomic net present value}

The $\mathrm{LCOH}$ was calculated as the total cost over the project lifetime of 20 years divided by the total amount of heat delivered in the same period. The total cost was defined as all cost occurring during the project lifetime discounted to the first year of the project, i.e. 2023, including the residual values of components with a longer lifetime and investment into replacement of components with a shorter lifetime.

The socioeconomic NPV was calculated according to Danish guidelines [30] as the socioeconomic cost of the $\mathrm{DH}$ project, i.e. all investment and operation costs plus emission cost, compared to individual heat supply with air-source heat pumps. Taxes and tariffs were not included in the socioeconomic cost.

\subsubsection{Fuel cost and taxes}

Electricity and emission price projections were based on projections from 2016 for the period 2012 2040 by Energinet.dk [31], where the emission prices were based on IEA projections [32]. Local conditions such as electricity tax, network- and system tariffs and distribution tariffs were considered.

\subsubsection{Assumed cost data}

The total investment cost of the system comprised the investment in central units, decentral HPs and the network itself. The functions for investment cost, and assumed lifetimes are listed in Table 1. Fixedand variable O\&M cost were taken from the Danish Technology Catalogue [33-35]. A linear cost function was used to describe the fixed O\&M cost of booster HPs in $€ /$ unit/a, which was derived from [33], and uses $\dot{Q}_{\text {booster,nom in } M W \text {. }}$

$$
C_{\text {fixedom,booster }}=229.6+3852.6 \cdot \dot{Q}_{\text {booster, nom }}
$$

Table 1 Investment cost for energy conversion units. *Correlation fitted through cost data given in the stated sources

\begin{tabular}{lccc}
\hline \multicolumn{1}{c}{ Technology } & $\begin{array}{c}\text { Investment cost function } \\
{[\mathrm{M} € / \mathrm{MW}]}\end{array}$ & $\begin{array}{c}\text { Lifetime } \\
{[\mathrm{a}]}\end{array}$ & Sources \\
\hline $\begin{array}{l}\text { Excess heat HEX } \\
\text { installation }\end{array}$ & $0.260 \cdot \dot{Q}_{\text {nom }}^{-0.1234}$ & 20 & {$[36]$} \\
Central HP excess heat & $0.867 \cdot \dot{Q}_{\text {nom }}^{-0.1234}$ & 25 & {$[36][37]$} \\
Central HP groundwater & $1.112 \cdot \dot{Q}_{\text {nom }}^{-0.23105}$ & 25 & {$[36]$} \\
Central HP air & $0.937 \cdot \dot{Q}_{\text {nom }}^{-0.1418}$ & 25 & {$[36]$} \\
Central Electric boiler & 0.11 & 20 & {$[34]$}
\end{tabular}




\begin{tabular}{lccc} 
Central gas boiler & 0.06 & 25 & {$[34]$} \\
Indv. Air to water HP & 0.95 & 15 & {$[34]$} \\
Booster HP & $2.748 \cdot \dot{Q}_{\text {nom }}^{-0.594}$ & 15 & {$[8,38-40]^{*}$} \\
DH substation & $0.414 \cdot \dot{Q}_{\text {nom }}^{-0.536}$ & 25 & {$[33,39]^{*}$} \\
\hline
\end{tabular}

\section{Results}

\subsection{System performance}

\subsubsection{Duration load curves of heat production}

Figure 4 shows the duration load curves of the heat production of four DH cases. The heat demand was the same and thus the difference in heat supplied was small and only caused by differences in heat loss. For ULTDH-DH and ULTDH-DH-micro, DH represented the heat source for the DHW heat pumps, depicted as the light grey area. Thus, the heat added to the system by the booster unit (black area) was equivalent to the power uptake of the units. In the ULTDH-air case, the decentral heat pump used air as heat source and thus the heat added to the system was all the heat supplied from the condenser.
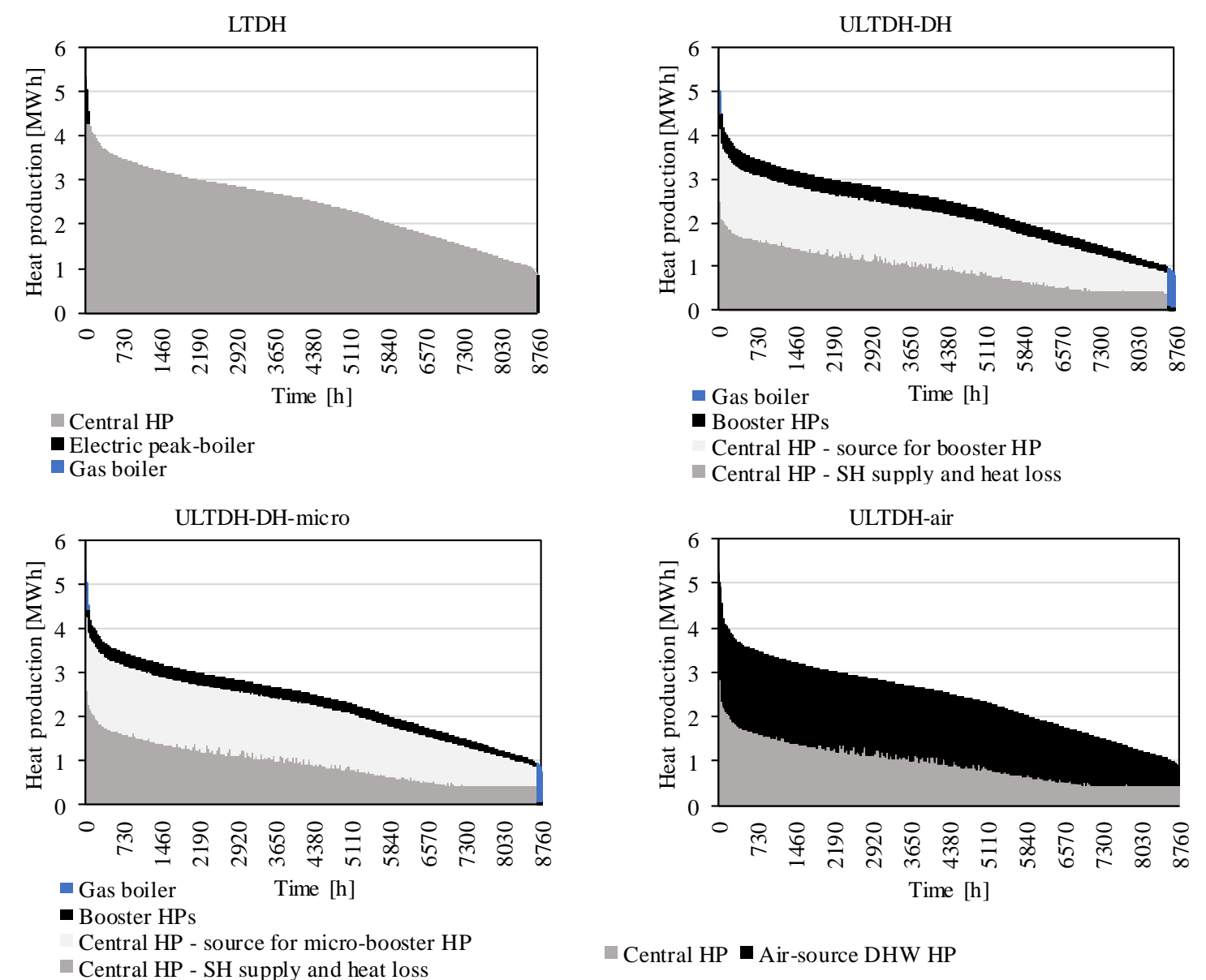

Central HP $\square$ Air-source DHW HP

Figure 4 Duration curve for four DH cases supplied by a central HP for plot ratio $=1.5$, SH share $=0.5$

The heat demand increased with increasing plot ratio, as more customers were supplied in the same area. An increase in the SH share led to a higher heat demand during the heating period, while the effect 
during summer was small as mainly DHW was needed. Accordingly, increasing SH shares led to more pronounced seasonal behaviour, i.e. a steeper load duration curve.

\subsubsection{Hourly variation of COP}

The hourly values of COP of all HP units for ULTDH and LTDH are shown in Figure 5. The COP of the central units was higher for the ULTDH cases, as the supply temperature was lower compared to LTDH. A seasonal variation is observed for all units. It is most pronounced for air-source heat pumps as the heat source (air) temperature varies strongly throughout the year. The variation of the other units was caused by increased forward temperatures during winter. This led to higher temperature lifts in the central units. The booster HP COP was affected, too, as sink and source inlet temperatures increased, while the supply temperature and the controlled return temperature stayed constant. In consequence, this led to an increased condensation pressure and thus reduced COP.
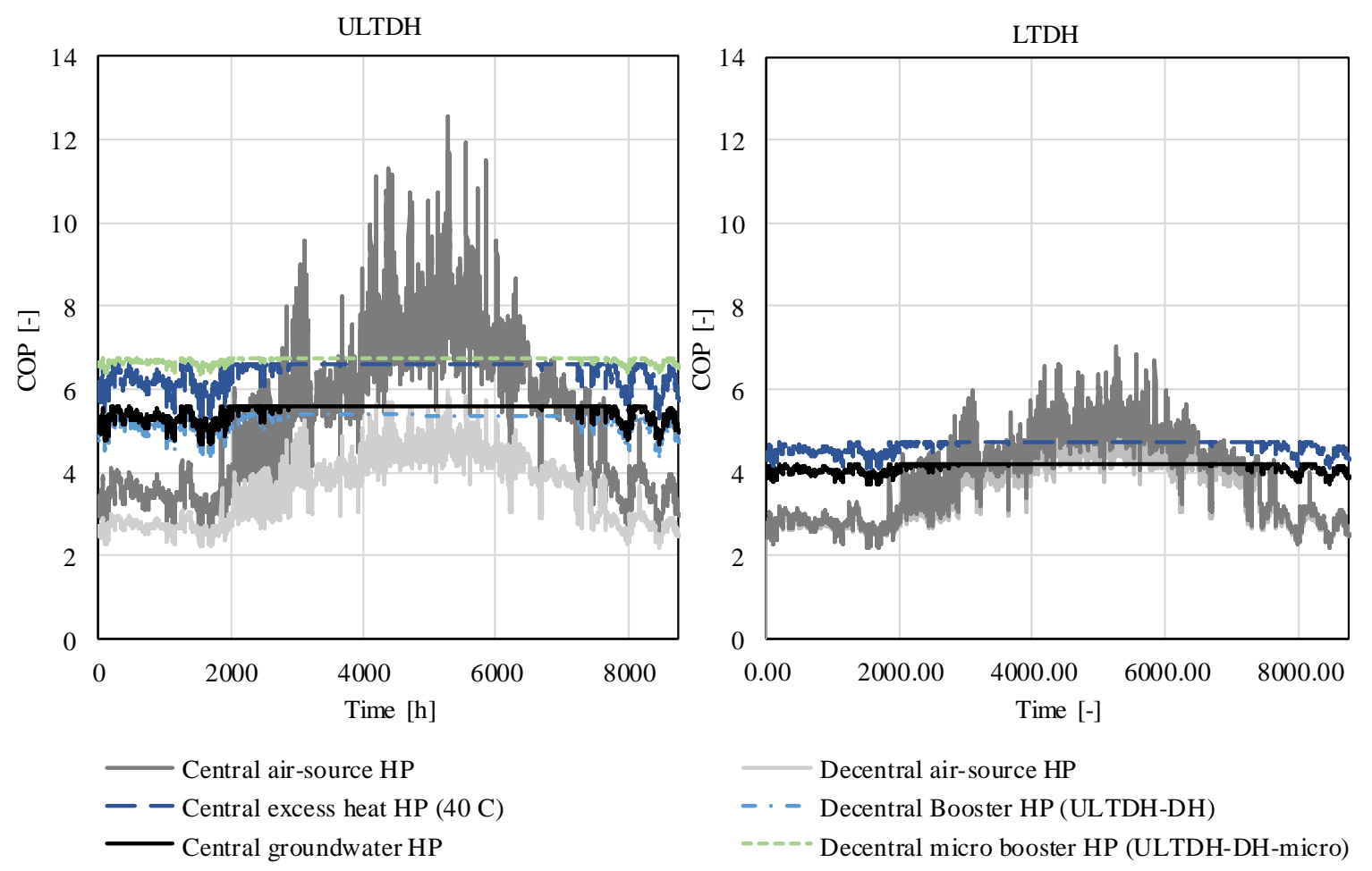

Figure 5 Hourly variation of COP for one year of all considered heat pump units for ULTDH and LTDH

\subsubsection{Dependency of seasonal system COP on plot ratio and SH share}

Figure 6 shows the seasonal system COP for excess heat of $40^{\circ} \mathrm{C}$ and air-source HP as the central unit. The results for groundwater HP as central unit are not depicted, but show a similar trend to that of the air-source HP. For LTDH the seasonal system COP increased from $0.1 \mathrm{SH}$ share and reached a maximum at a SH share of 0.6 and a plot ratio of 2 for HP using excess heat at $40{ }^{\circ} \mathrm{C}$. For air-source HP and groundwater HP, the maximum was reached at a SH share of 0.3 and 0.6 , respectively. For plot ratios larger than 0.7 the COP dropped again. Reductions in COP for low and high SH shares were connected to increased usage of the electric back-up boiler due to constraints of the HP capacity. 
The maximum seasonal system COP for air-source HPs was shifted towards lower SH shares compared to the alternatives. For air-source HPs a reduction of seasonal heat demand peaks due to lower SH shares in winter was advantageous, because the amount of heat produced with a reduced COP due to low source temperatures and defrosting could be reduced.
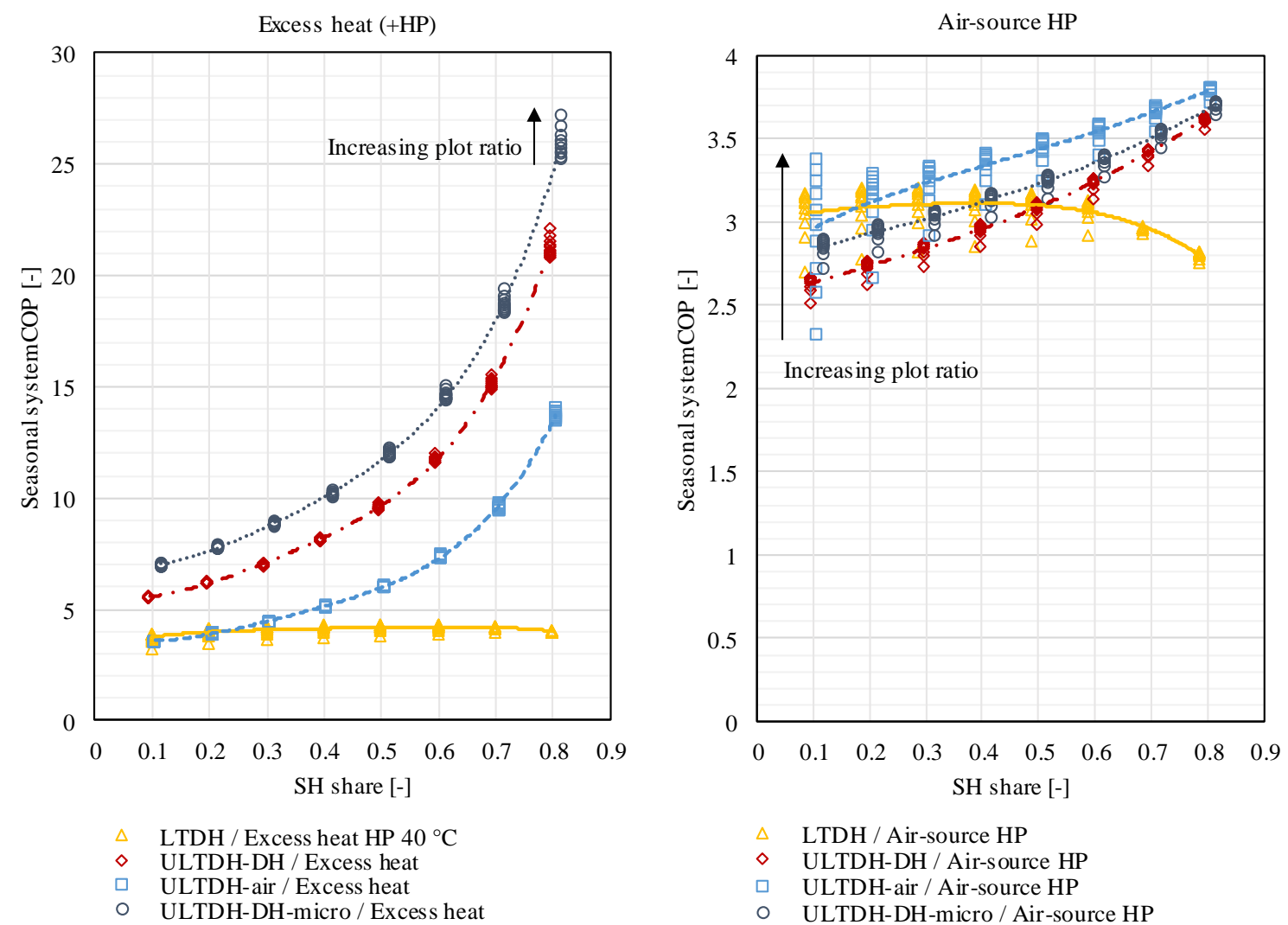

Figure 6 Seasonal system COP for four DH cases and two central heating units depending on the SH ratio. The data points presented are for plot ratios of $0.2,0.4, \ldots, 2$. Trend lines for the four different cases are shown.

The seasonal system COP increased with increasing SH share for all ULTDH solutions. For ULTDH-DH and ULTDH-DH-micro the DHW share of the heat supply had a lower COP than the heat supplied directly at $40{ }^{\circ} \mathrm{C}$. This was due to the necessary additional electricity input to lift the temperatures to the desired level. Accordingly, larger shares of SH resulted in larger average COPs, as the share of directly supplied heat increased. However, increased SH shares meant less energy efficient buildings and a higher overall heat demand. The same trend was observed for ULTDH-air. Here, the system COP increased as the central HP had a better COP than the booster HP as shown in section 3.1.2.

For the excess heat case, the ULTDH solutions, which were supplied by excess heat directly, clearly outperformed LTDH, where a HP was needed to supply the necessary forward temperatures. ULTDHDH-micro had the highest seasonal COPs, followed by ULTDH-DH and ULTDH air. This can be explained by the difference in COP between the micro-booster HP (6.7), the booster HP (5.2) and the decentral airsource HPs (3.1-3.3). For the booster HPs, a higher COP meant that more heat was supplied from the 
central source, and thus a higher share of heat was supplied directly from excess heat, which increased the overall seasonal COP.

For ULTDH supplied by a central air-source HP, the seasonal COP of the different DH cases is much closer to each other and ULTDH-air performed best for most cases. For low SH shares the COP of ULTDH-air was highly sensitive to the plot ratio, indicated by the larger spread of the data points in y-direction indicated by the arrow in the diagram. This was caused by an increase in relative heat loss for very low heat demands. For SH shares of 0.4 and higher or plot ratios of 0.8 and higher ULTDH-air had the highest seasonal COP. This was because in the ULTDH-DH and ULTDH-micro cases, DHW was produced by two heat pumps in a row, which led to a lower COP than the decentral air-source HP COP for the DHW demand share. The difference between ULTDH-DH-micro and ULTDH-DH is caused by the difference in booster HP COP.

For $\mathrm{DH}$ supplied by a groundwater HP, the trends looked similar to those for the central air-source HP. LTDH yielded the highest seasonal COP up to SH shares of 0.4. For higher SH shares ULTDH was more efficient. Among the three different ULTDH variants, ULTDH-air performed best followed by ULTDH-DHmicro and ULTDH-DH.

\subsection{Levelised cost of heat}

The $\mathrm{LCOH}$ of 12 exemplary cases are depicted in Figure 7 a). The LCOH decreased with increasing plot ratio and with increasing SH share. The overall findings showed that LTDH was cheaper than the ULTDH systems in most calculated scenarios. The difference was largest for low SH demands, i.e. highly energy efficient buildings, and low plot ratios. Among the ULTDH solutions, ULTDH-DH-micro was only competitive for low plot ratios where the number of installed micro-booster units and alternative units was similar. For increasing plot ratios, multi-family buildings were considered and the booster HPs benefitted from economy of scale and thus ULTDH-DH got more beneficial. ULTDH-air could only be competitive for relatively high $\mathrm{SH}$ shares, as only the $\mathrm{SH}$ is distributed through $\mathrm{DH}$, and thus all the cost of installing a network and a central unit was assigned to the $\mathrm{SH}$ cost only.

Figure 8 a) shows the most feasible supply options for varying SH share and plot ratio. Individual heat supply from air-source heat pumps was most feasible at low plot ratios and low SH shares. It was observed that the LHDD alone is not enough to describe the feasible area precisely, but instead both SH share and plot ratio should be considered. Figure $8 \mathrm{~b}$ ) compares the most feasible $\mathrm{DH}$ variants for direct excess heat supply, LTDH supplied by a heat pump using a $40^{\circ} \mathrm{C}$ source and individual heat supply. In this case, ULTDH was beneficial compared to LTDH for buildings with a SH share of approximately 0.7 or more and for plot ratios above approximately 1.0 for ULTDH-DH and 1.8 for ULTDH-air.

Figure 9 compares the $\mathrm{LCOH}$ for different central heating units. The changes in $\mathrm{LCOH}$ between the different central units was small compared to the change due to different DH system designs. The LCOH did not change significantly with decreasing excess heat temperatures for those cases, where a central heat pump was used, as it was assumed that all excess heat streams were cooled down to $10^{\circ} \mathrm{C}$. This heat source outlet temperature determined the evaporation pressure, and thus no COP improvement was obtained. For the ULTDH solutions, the investment cost for the central unit increased significantly, when the excess heat temperatures were too low to supply SH directly.

As the heat source was the main energy supply of the system, its cost could significantly influence the feasibility of the solution. For the case presented in Figure 9, HPs using excess heat at a cost of 
$10 € / M W h$ led to higher $\mathrm{LCOH}$ than both natural sources for all variants but ULTDH-air. HPs using excess heat as source could lead to lower $\mathrm{LCOH}$ in case the cost of excess heat was reduced or the COP was increased, e.g. by allowing a higher source outlet temperature. The variation of excess heat cost did however not change the feasibility of the LTDH solutions compared to the ULTDH solutions. 
SH share $=0.5$

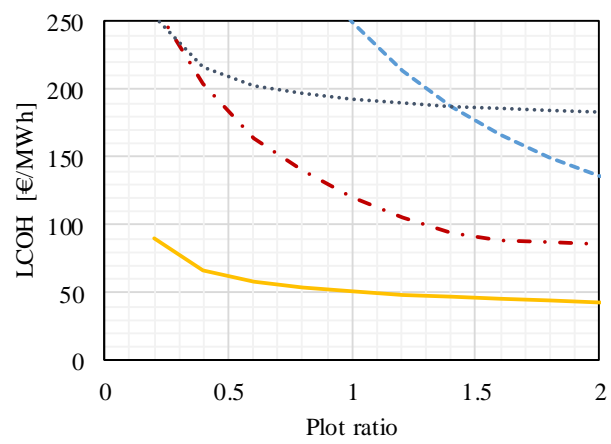

$$
- \text { LTDH }
$$$$
\text { Plot ratio }
$$

$$
\text { ----- ULTDH-air }
$$

$$
\text { - - - ULTDH-DH }
$$
... ULTDH-DH-micro

b) $\quad \mathrm{SH}$ share $=0.1$

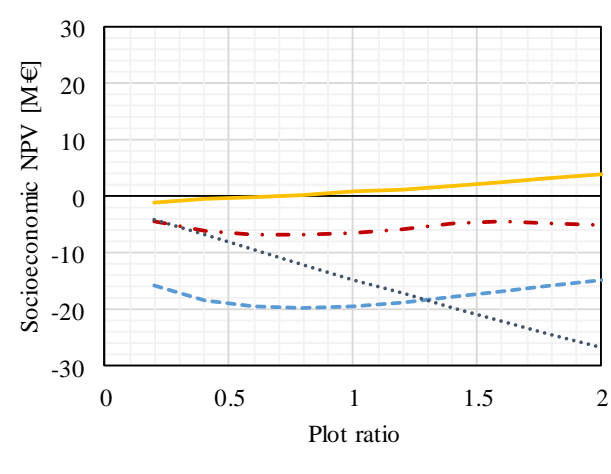

$$
\begin{array}{ll}
\text { - LTDH } & -\cdot-\text { ULTDH-DH } \\
\text {----- ULTDH-air } & \text {......... ULTDH-DH-micro }
\end{array}
$$

$-\mathrm{LTDH}$
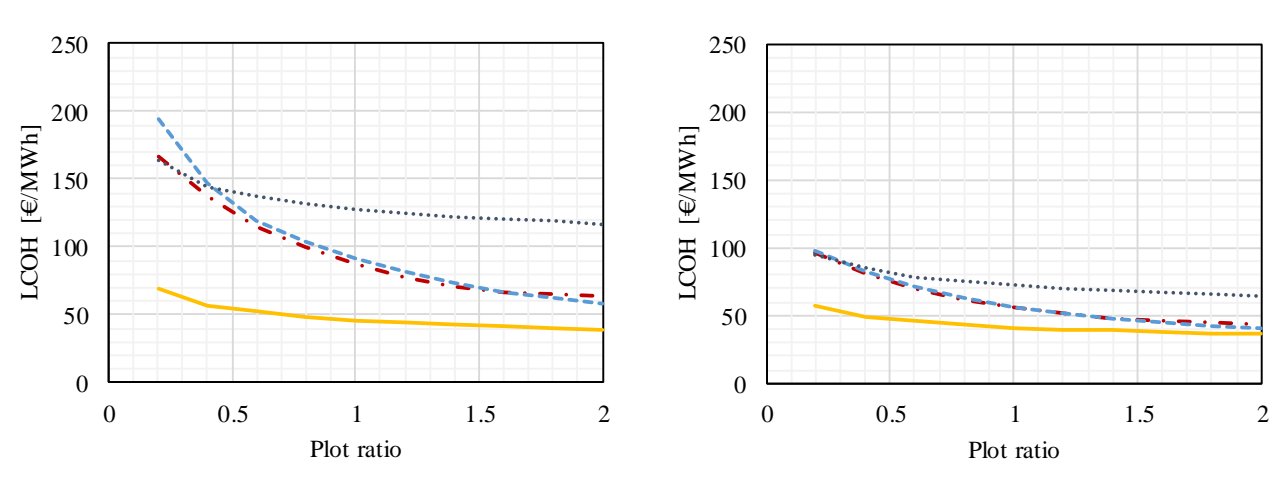

- - - ULTDH-DH

- LTDH

- - - ULTDH-DH ----. ULTDH-air …… ULTDH-DH-micro ----- ULTDH-air ULTDH-DH-micro
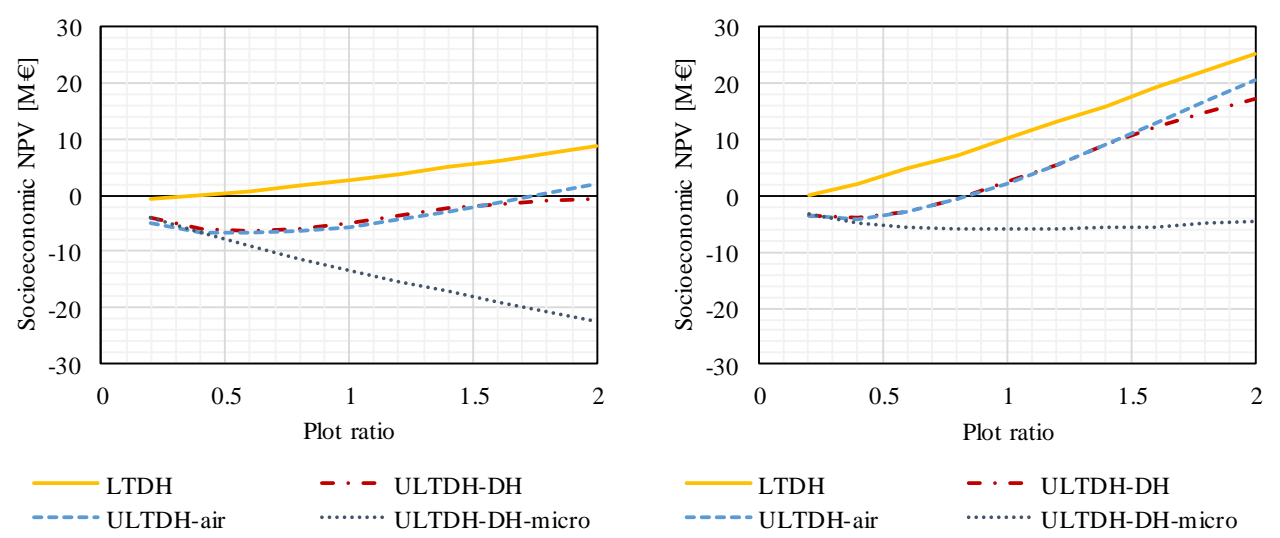

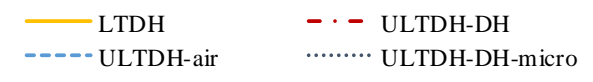

Figure 7 a) Levelised cost of heat depending on the plot ratio for three different SH shares, central heat source: Groundwater HP; b) Socioeconomic NPV depending on plot ratio for three different SH shares, central heat source: Groundwater HP 
a)

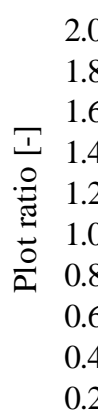

0.2

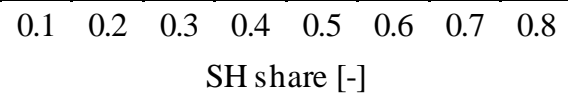

LTDH Groundwater HP

Indv. Air-source HPs b) Most feasible DH variant supplied by excess heat

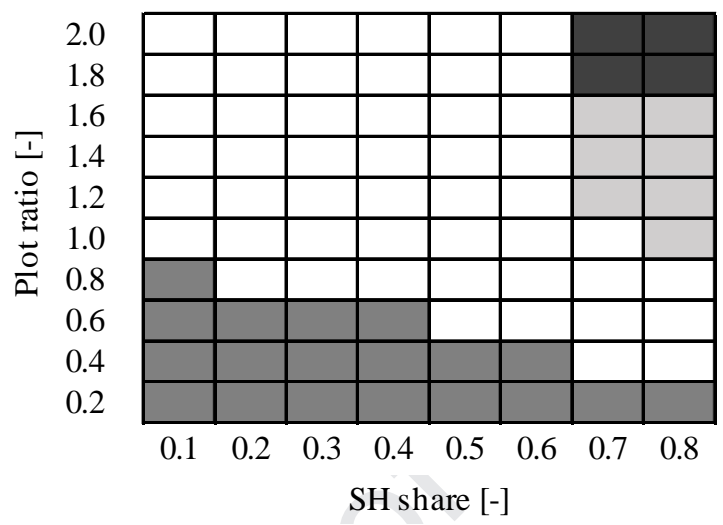

$\square$ LTDH Excess heat $40^{\circ} \mathrm{C} \mathrm{HP}$

Indv. Air-source HPs

ULTDH-DH direct supply by excess heat

ULTDH-air direct supply by excess heat

Figure 8 a) Most feasible supply solution comparing all technology combinations, b) most feasible DH variant when the heat is supplied by excess heat directly for ULTDH and by a heat pump using $40^{\circ} \mathrm{C}$ excess heat as heat source compared to supply from individual

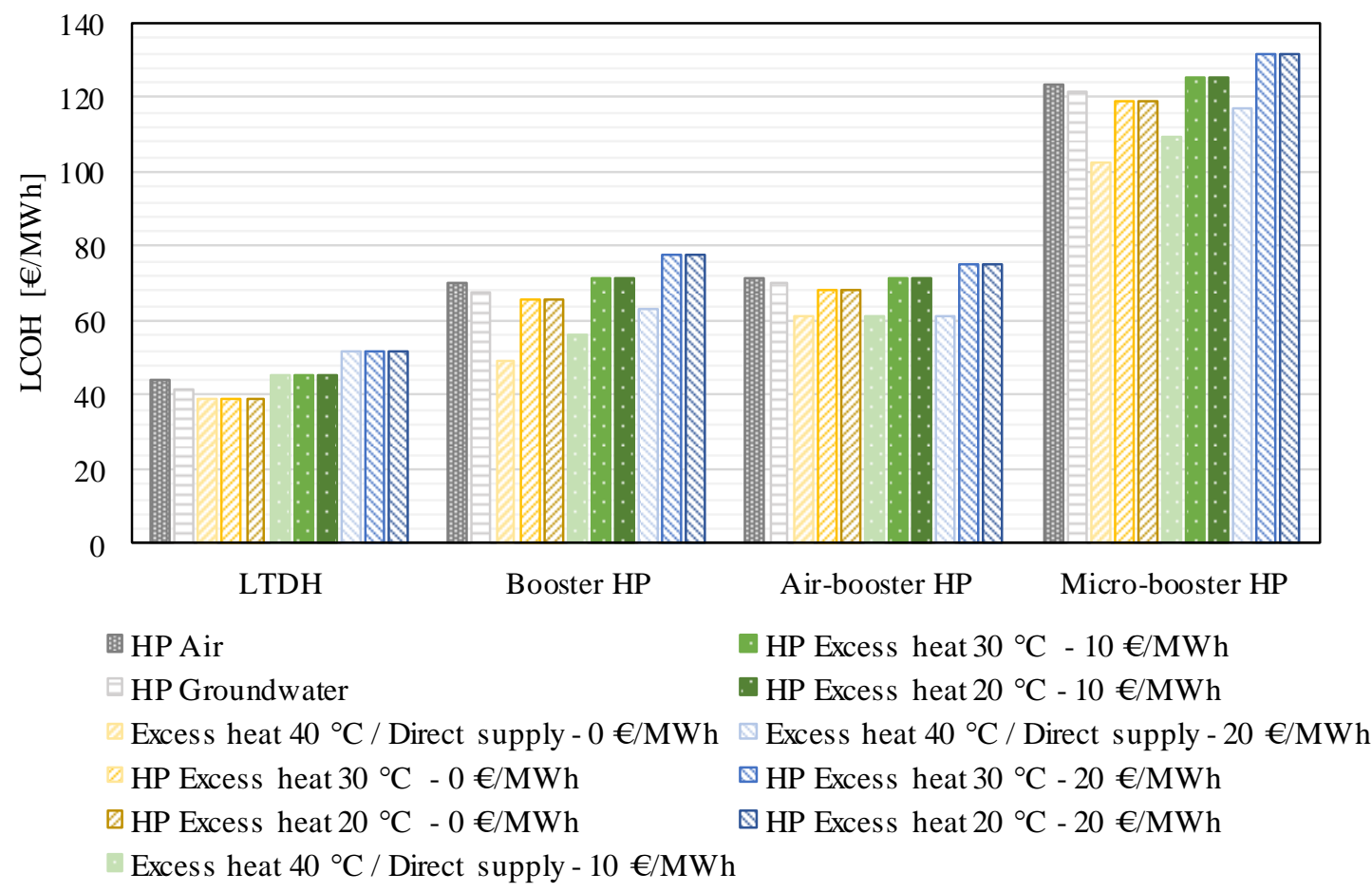

Figure 9 Levelised cost of heat for different central heat sources and excess heat cost for SH-share $=0.5$ and plot ratio $=1.5$ 
The influence of the supplied area size on the results was low compared to the other parameters presented. A reduction in area size resulted in higher specific costs for all solutions due to economy-ofscale effects. The increase in specific cost was largest for LTDH and lowest for ULTDH-DH-micro. This resulted in a slight shift of where ULTDH solutions may be feasible towards lower heat demand densities.

\subsection{Socioeconomic net present value}

The socioeconomic NPV for the same cases shown in section 3.2 is depicted in Figure 7 b). The socioeconomic NPV is a relative value showing the difference between the DH solution and heat supply based on individual air-source heat pumps. Accordingly, a positive value was equivalent to a socioeconomic PV larger than that of individual air-source HPs and a negative value meant that individual air-source HPs were most feasible. In the depicted cases this was the case for a plot ratio below $0.63,0.39$ and 0.2 for $\mathrm{SH}$ shares of $0.1,0.5$ and 0.8 , respectively.

Generally, the socioeconomic NPV increased with increasing plot ratio if the LCOH of the DH solution was below the $\mathrm{LCOH}$ of heat supply based on individual air-source HPs. This shows good agreement between the private consumer economy and the socioeconomic results. The gradient of the socioeconomic NPV curve depended on the gradient of the cost difference between the DH- and the individual solution, and the gradient of the overall heat supply with increasing plot ratio.

\subsection{Cost composition}

To understand what determines the economic feasibility of ULTDH and LTDH, the cost composition of the $\mathrm{DH}$ solutions was analysed. Figure 10 shows the cost composition for the four $\mathrm{DH}$ solutions, supplied by a groundwater $\mathrm{HP}$, for $\mathrm{SH}$ shares of 0.5 and 0.8 and plot ratios of 0.6 and 2 . The same trends were observed for all central HPs.

For all four cases depicted in Figure 10, LTDH was economically most feasible, despite the lower overall seasonal COP (see section 3.1). Among the ULTDH solutions, the total cost was lowest for ULTDH-air, followed by ULTDH-DH and ULTDH-DH-micro. The cost of the ULTDH-DH-micro was considerably higher compared to the alternatives, especially for the case with a plot ratio of 2 . This had two major reasons. First, the investment cost of micro-booster units was 2.87 times the investment cost of the air-source HPs. This was due to the constant specific investment cost of the micro-booster HPs, which always came in the same size as they were installed in every apartment. The specific cost of the air source HP and the booster HP decreased due to economy-of-scale effects with increasing plot ratio, as the buildings got larger and thus the HP size increased. Second, the fixed O\&M cost was 16.7 times higher than that for air-source HPs. This was due to the larger number of installed units that would have to be operated and maintained. The difference was less relevant for areas with lower plot ratio, where the number of apartments per building decreased. This is represented by the case of SH share of 0.8 and plot ratio of 0.6 , where the total cost of the three ULTDH solutions were closer to each other.

The investment and O\&M costs of the decentral HP units solely depended on the plot ratio, i.e. the total number of buildings and the number of apartments per building. Accordingly, the differences between the DH variants were more pronounced for lower SH shares. With an increasing SH share the capacity of the central heat pump unit increased and accordingly, the investment cost of the central heating unit and the total heat production cost from the central heating unit increased. The heat production cost of the central unit included electricity cost, variable O\&M cost and taxes. The investment cost of the 
central unit supplying ULTDH at high plot ratios was slightly higher than for LTDH. This was caused by the assumption that the capacity of the central units for ULTDH should have capacity to cover the maximum DH demand, while the capacity of the LTDH central unit was assumed to be only $80 \%$ and instead an additional peak boiler was included. Accordingly, the lower investment cost in the central unit for LTDH led to relatively high heat production cost of the peak load boiler, indicating that the capacity of the central unit should be optimized.

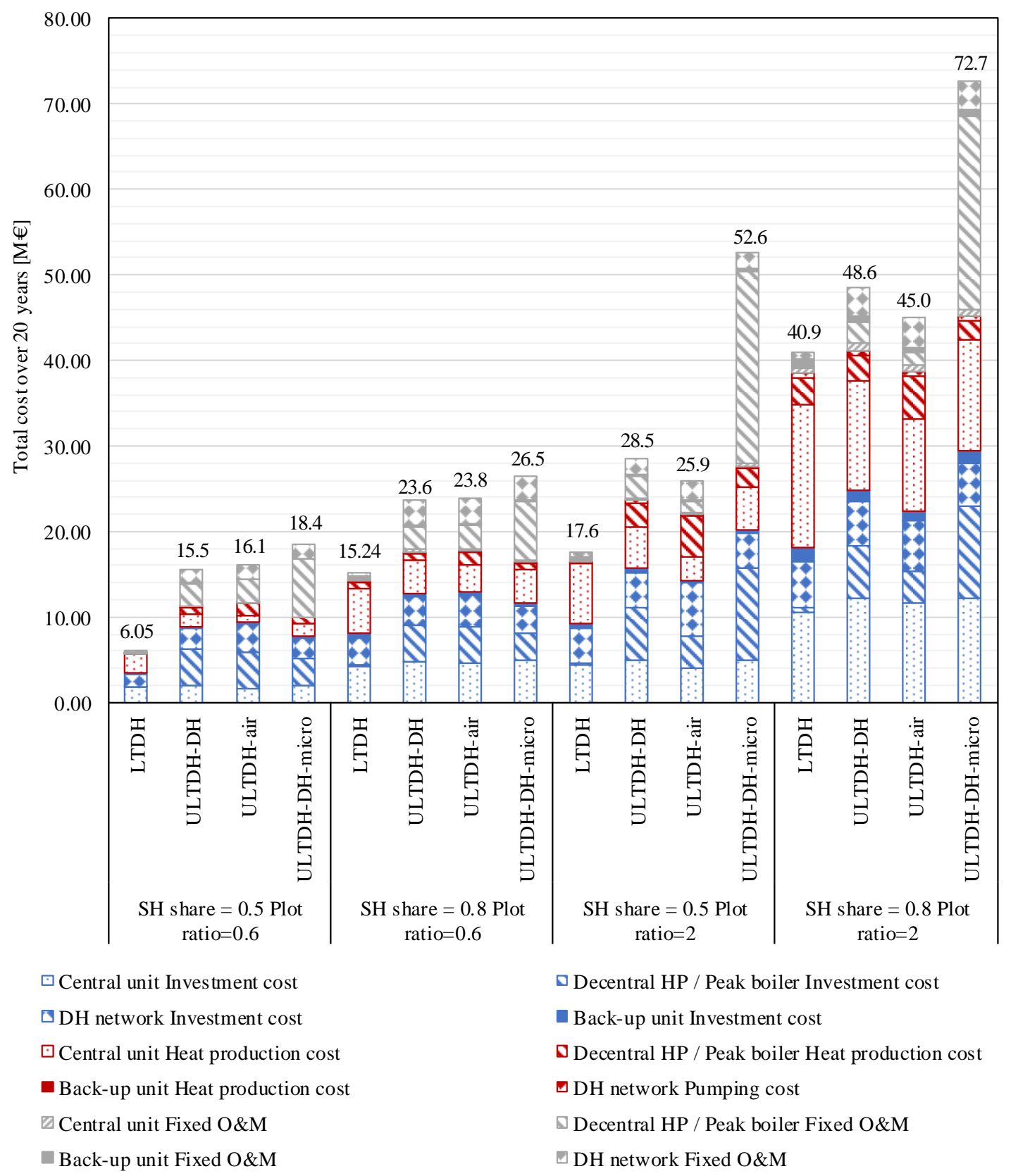

Figure 10 Cost composition for $\mathrm{SH}$ share $=0.5$ and $\mathrm{SH}$ share $=0.8$, plot ratio $=2$ and plot ratio $=0.6$, central heating source: Groundwater HP. Heat production cost includes variable O\&M cost, fuel costs and taxes. Investment cost includes VAT, reinvestments and the residual value has been subtracted. DH substation cost is included in fixed O\&M cost of the DH network. 


\subsection{Sensitivity analysis}

\subsubsection{Variation of investment cost}

The HP investment cost were based on currently available technology and recent projects, but they might decrease due to higher production volumes in the future. The investment cost was varied for the central HPs, decentral HPs and the network. The results are presented in Figure 11 for a SH share of 0.8 and a plot ratio of 2, as this was the cases were the LCOH of ULTDH was closest to LTDH. The results are presented as the difference between the LCOH of the ULTDH solution and the LTDH solution, i.e. a negative value meant that ULTDH is more feasible than LTDH in terms of LCOH
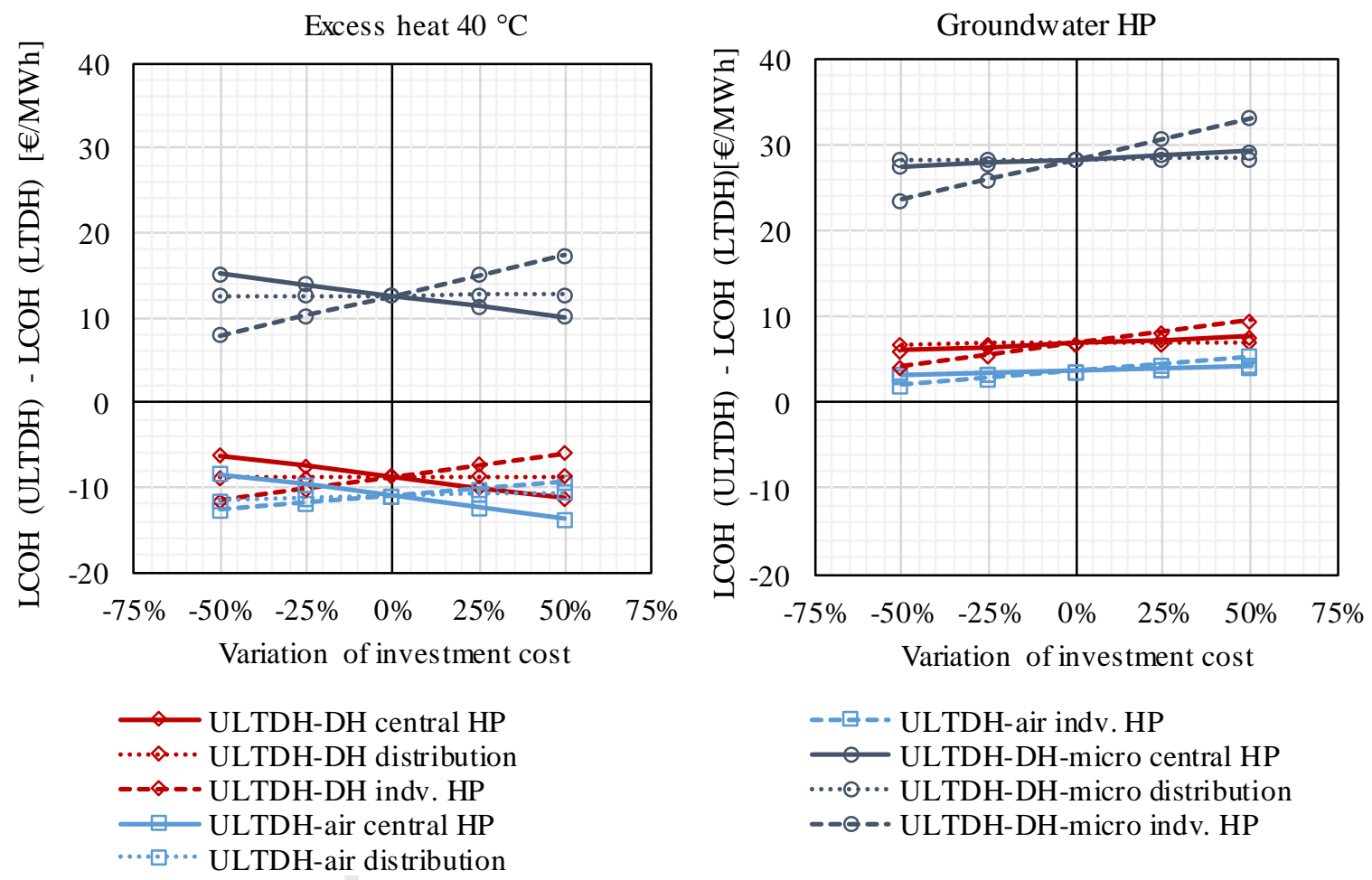

Figure 11 Variation of investment cost of central heating unit (central), decentral booster HPs (individual) and DH network (distribution) for excess heat $40^{\circ} \mathrm{C}$ source HP / direct excess heat supply and groundwater HP as central heating units, plot ratio $=2$ and $\mathrm{SH}$ share $=0.8$

All investment cost changes resulted in a linear change in LCOH difference. The change in network investment was similar for all $\mathrm{DH}$ variants and did not result in a significant change in the difference of $\mathrm{LCOH}$. A lower investment in decentral HPs resulted in a decrease in LCOH difference. The effect was most significant for ULTDH-DH-micro, which had the highest decentral HP investment cost. An increase of the investment in the central unit resulted in a decrease of the $\mathrm{LCOH}$ difference in the case of excess heat, as the investment cost in the heat pump needed for LTDH supply were significantly higher than the cost of the central heat exchangers for direct use of excess heat in ULTDH. For groundwater HP as a central unit, both DH solutions required the investment in a central HP and LTDH benefitted from economy of scale due to the larger necessary capacities. Accordingly, the LCOH difference increased with increasing central unit investment cost. The feasibility of LTDH or ULTDH did not change for the depicted cases. 


\subsubsection{Variation of COP}

The COP of the central and decentral HPs were varied between $-25 \%$ and $+50 \%$ [41] to account for possible innovations in heat pump technology. Such an increase might e.g. be obtained through the use of zeotropic mixtures as working fluids as proposed by Zühlsdorf et al. [38].The results are presented in Figure 12 for the same cases shown in Figure 11. A reduction in COP of the central and decentral HPs, had a larger influence on the LCOH difference than an increase. An increase in the decentral HP COP benefitted the ULTDH solutions. An increase in central HP COP benefitted the LTDH solution. ULTDH-air benefitted most from an increase in decentral HP COP, i.e. a higher share of heat that could be recovered from the outside air. Testing the influence of a decrease in decentral HP COP for ULTDH-air also gives an indication of how large the influence of neglecting the fan power consumption on the result may be. ULTDH-DH and ULTDH-DH-micro benefitted less from an increase in booster HP COP, which led to an increased heat production from the central HP and a larger capacity of the central HP.
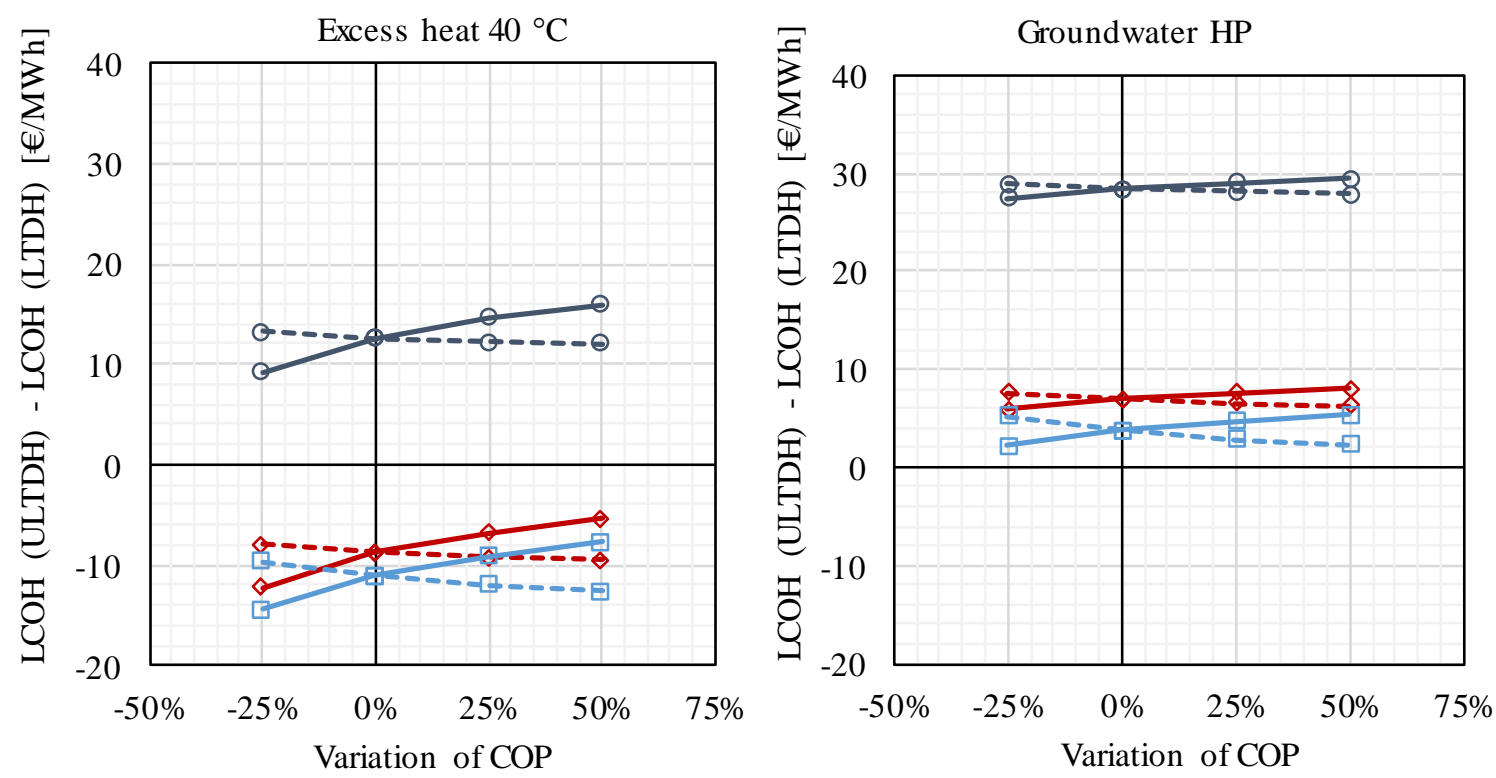

$$
\begin{aligned}
& --\diamond-- \text { ULTDH-DH indv. HP } \\
& --\boxminus-- \text { ULTDH-air indv. HP } \\
& --\ominus-- \text { ULTDH-DH-micro indv. HP }
\end{aligned}
$$

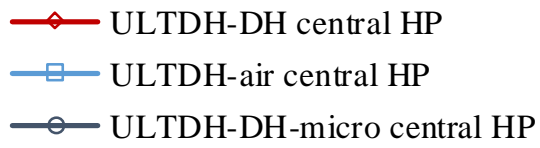

Figure 12 Variation of COP of central HP and booster units for excess heat $40^{\circ} \mathrm{C}$ source $H P$ / direct excess heat supply and groundwater HP as central heating units, plot ratio $=2$ and $S H$ share $=0.8$

The influence of neglecting the fan power consumption of the air-source HPs on the overall feasibility of LTDH and ULTDH compared to heat supply by individual air-source HPs was tested. Figure 13 shows the variation of the minimum plot ratio for that LTDH is still feasible with increasing fan power consumption. The fan power was varied between $0 \%$ and $11 \%$ of the HP compressor power consumption. The minimum feasible plot ratio for LTDH is reduced with increasing fan power ratio, as the operation cost of individual HPs increases and thus LTDH is competitive for less densely built areas. The effect is strongest for low SH shares, as the LCOH of LTDH and the LCOH of individual HPs cross each other at larger plot ratios, where the LCOH curve of LTDH is flatter than at lower plot ratios (compare Figure 7). 


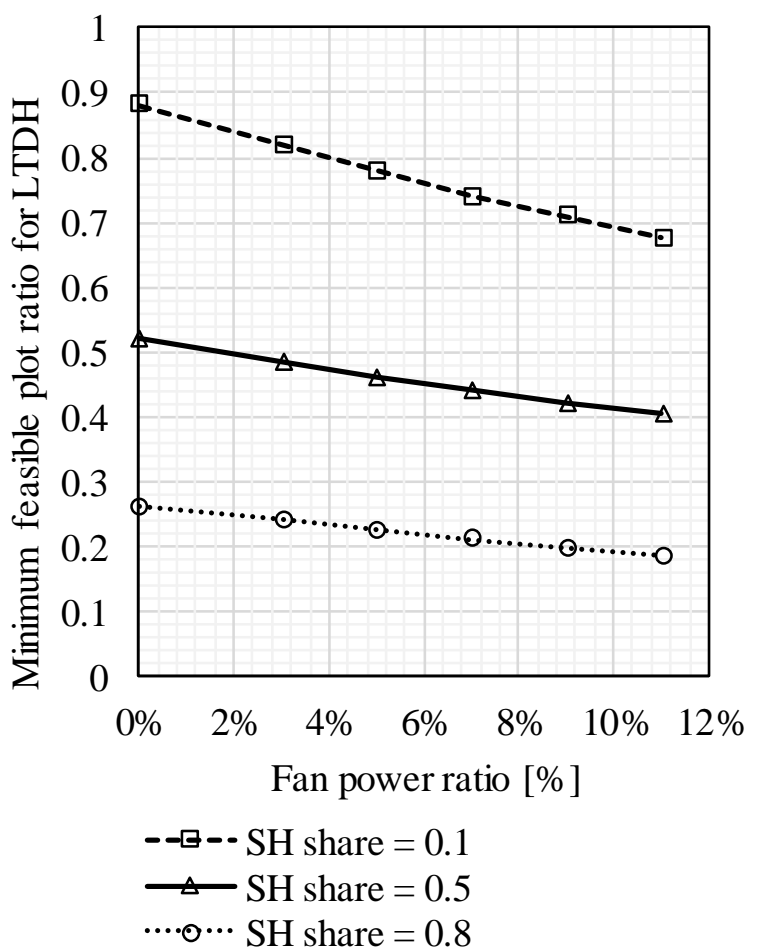

Figure 13 Variation of minimum feasible plot ratio for LTDH with fan power ratio for SH shares of $0.1,0.5$ and 0.8 . Fan power ratio was defined as the total annual fan power consumption over the total annual compressor power.

\subsubsection{Variation of electricity cost}

The electricity cost was varied, as the future electricity price development is uncertain. A decrease in electricity price increased the LCOH difference slightly and thus benefitted the LTDH solution. ULTDH solutions benefitted from increased electricity prices, as the seasonal system COP is highest for the ULTDH options, i.e. less power is consumed per unit heat delivered. The effect was largest for ULTDHDH-micro and least for ULTDH-air. The feasibility of the solution for the case of a SH share of 0.8 and a plot ratio of 2.0 did not change with a decrease or increase of the electricity price of $50 \%$.

\subsubsection{Variation of full load hours of decentral HPs}

The design full load hours per year for the decentral HP units of ULTDH-DH and ULTDH-air were varied from $1000 \mathrm{~h}$ to $4000 \mathrm{~h}$. The results are presented in Figure 14. The LCOH difference decreased with increasing number of design full load hours, as the installed capacity and thereby the investment cost decreased. The trend was more pronounced for ULTDH-DH, than for ULTDH-air. Further, the decrease was lowest for the case with the highest SH share and plot ratio. Accordingly, lower decentral HP capacities would benefit the ULTDH solutions compared to the LTDH, but in the assessed range LTDH was still economically more feasible. 


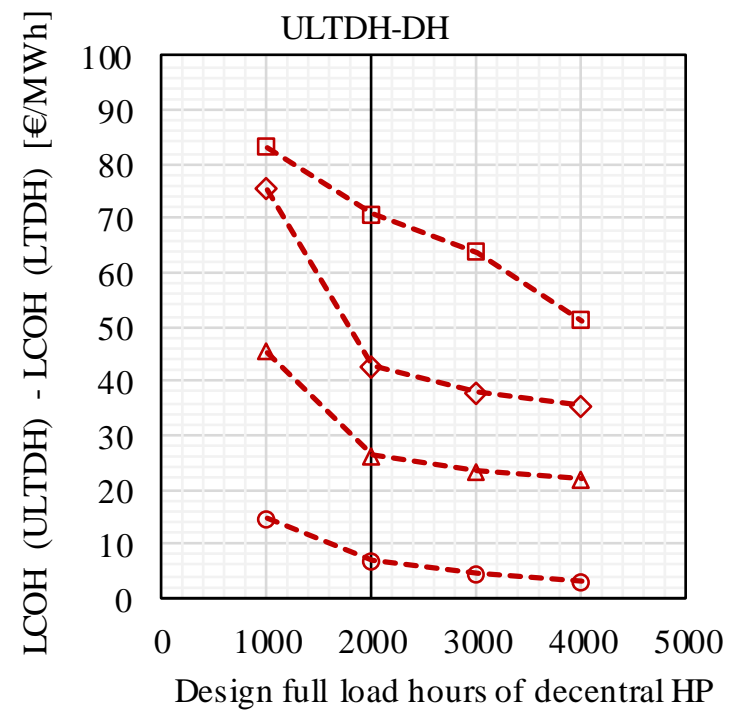

$--\Theta-\cdot$ Plot ratio $=0.8 \mathrm{SH}$ ratio $=2$

$--\star-\cdot$ Plot ratio $=0.5 \mathrm{SH}$ ratio $=1.5$

$--\square-\cdot$ Plot ratio $=0.5 \mathrm{SH}$ ratio $=0.5$

$-\diamond-\bullet$ Plot ratio $=0.15 \mathrm{SH}$ ratio $=1.5$

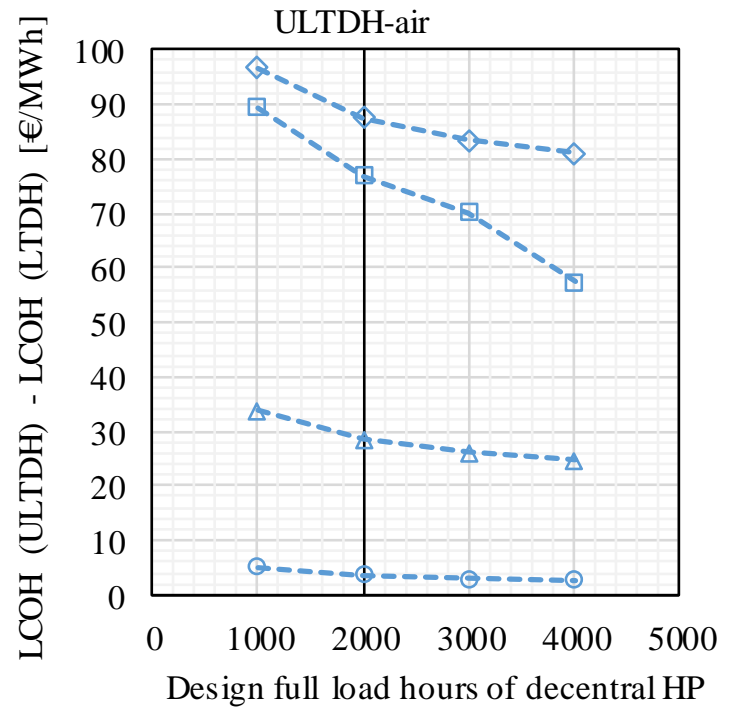

$--\ominus--$ Plot ratio $=0.8 \mathrm{SH}$ ratio $=2$

$--\Delta--$ Plot ratio $=0.5 \mathrm{SH}$ ratio $=1.5$

$--\boxminus--$ Plot ratio $=0.5 \mathrm{SH}$ ratio $=0.5$

$-\backsim \diamond-\bullet$ Plot ratio $=0.15 \mathrm{SH}$ ratio $=1.5$

Figure 14 Variation of design full load hours of decentral HPs for groundwater HP as central heating unit for four cases

\section{Discussion}

The aim of the current study was to deduce under which boundary conditions ULTDH could be feasible compared to LTDH in Denmark. To answer this question, general correlations were used, which means that the results showed a general trend. Specific local conditions might change the results and a more thorough analysis would be needed for evaluating the feasibility of all heat supply solutions for a specific case. This would also allow for optimal sizing of the central unit with regard to the expected heat demand profile, which was not in the focus of the current study.

The current study focused on large-scale heat pumps and excess heat as central heat sources. The excess heat source has not been specified further and might as well represent other natural heating sources. In this case, seasonal temperature changes might occur, which should be considered, as they may influence the HP performance and necessary capacity. The case of $40^{\circ} \mathrm{C}$ excess heat as heat source for a heat pump might also give an indication of the feasibility of new areas connected in cascade to the return line of existing networks.

The case of direct excess heat supply of ULTDH is a theoretical scenario, which was included as an extreme scenario that could maximise the benefit of ULTDH solutions. It should be noted that the existence of such a source, which can deliver $40{ }^{\circ} \mathrm{C}$ and higher forward temperatures e.g. as excess heat from industrial processes is a special case and if available, could be expected to not be free of charge and without demand for power.

As the network design was unknown for the conducted study, the pumping power and heat loss values could only be estimated. As the pumping power made up a minor part of the overall energy use, the 
uncertainty was deemed acceptable. The heat loss was obtained from average values of existing Danish networks. Newly built networks might perform better due to modern piping technology, but representative data for ULTDH networks is missing. Another simplification made is that the return temperature can be kept constant. This is generally not achieved as the cooling of the DH stream varies with the supply temperatures and the overall heat demand [24]. It may be expected that the return cannot be cooled down to the assumed values during summer. The uncertainty introduced by this was integrated in the heat loss estimation, as it was based on empirical data. It might however, result in a decreased COP of the central HP during summer, which was not considered in this study.

As presented in section 3.4 the fixed O\&M cost for the booster units led to comparably high total cost of ULTDH-DH-micro. The cost function for the fixed O\&M cost was based on experiences with existing individual air source and ground source HPs [33]. As the heat source for the micro-booster and booster $\mathrm{HP}$ is the DH system, the O\&M cost related to the source might be less compared to ambient heat sources, as pollution and other risks connected to the ambient sources might be avoided. Further, these units are prefabricated, which might allow for reduced O\&M cost. This would decrease the LCOH difference between LTDH and ULTDH and increase the competitiveness of micro-booster HPs. However, reliable fixed O\&M cost data based on existing booster and micro-booster HPs is missing and should be addressed in future studies to reduce uncertainties for future projects.

The economic feasibility of the ULTDH-air and ULTDH-DH suffered from the extra investment and O\&M cost for the decentral HP units, even though the overall seasonal COP was higher than for LTDH if the LHDD of the supplied area were high enough. Accordingly, these cost components should be reduced. This may e.g. be achieved by reducing the capacity and thereby increasing the full load hours of the decentral units.

ULTDH could only be feasible under specific boundary conditions, i.e. a cheap heat source, which is available at temperatures high enough to supply SH directly, but not high enough for LTDH. It was shown that the cost for ULTDH are closest to LTDH when the network utilization is high, i.e. for high plot ratios, i.e. a densely populated area and high $\mathrm{SH}$ shares. This is an unlikely scenario for newly built quarters in Denmark, as the future building regulations do not allow for such high SH shares [20]. It has however been observed that buildings do not always behave accordingly [43], which justifies the assessment of $\mathrm{SH}$ shares of up to 0.8 . Another option to implement energy efficient ULTDH systems, while keeping the utilization of the $\mathrm{DH}$ network high may be the combination with district cooling, in so called cold district heating systems, e.g. [44]. This would require further research with regard to optimal system design and development of suitable heat pump substations.

The fan power of all air-source heat pumps was neglected. The sensitivity of this assumption was tested for ULTDH-air and for individual air-source heat pumps. It was not tested for central air-source HPs, as they were not among the best performing technologies and thus a change in COP of central air-source heat pumps would not change the results with regard to feasibility of ULTDH compared to LTDH and individual HPs. Miara [42] determined in field tests that the fan power consumption of small-scale airsource HPs is typically below $7 \%$ of the total power demand. Neglecting the fan power for the individual heat pumps led to more conservative results for the feasibility of LTDH for low linear heat demand densities. The feasibility of ULTDH-air compared to the other ULTDH solutions did not change when assuming a reduction in COP corresponding to $7 \%$ of the total HP power uptake. 
The results presented here are in good agreement with the results presented for specific cases in literature. It was confirmed that the operation cost is lower for ULTDH than for LTDH, as also found by Yang and Svendsen [2] and Elmegaard et al. [3]. However, the increased investment and O\&M cost for the ULTDH cases led to higher overall cost for the ULTDH cases. The case described by Best et al. [7] where they found that ULTDH was slightly better than LTDH considered a SH share of 0.8 and air-source HPs in a German case. According to the results presented here, this configuration might also be viable in Denmark if the plot ratio of the supplied area and the difference in central unit investment cost is large enough to balance out the extra investment in decentral units.

In the majority of the examined cases, LTDH was found to be economically more feasible than ULTDH. This was the case both in terms of $\mathrm{LCOH}$ and socioeconomic NPV. Both of these indicators evaluated the economy of the project from a public perspective. As the aim was to assess which common heating solutions could make sense in future applications, this approach seemed most feasible. It should be noticed that while the socioeconomic feasibility of heat supply solutions needs to be proven in order to realize a project in Denmark, this is not the case in most other countries and there the feasibility in terms of business and customer economy would probably be the decisive factor.

\section{Conclusion}

The aim of this study was to assess how the economic feasibility of LTDH and ULTDH systems is influenced by the boundary conditions of the supplied area and the available heat sources. For future suburban and urban (plot ratio above 0.6), newly built areas in Denmark supplied by heat pumps, heating supply from LTDH is economically most feasible. Generally, the LCOH for all considered alternatives decreased with increasing plot ratio and increasing $\mathrm{SH}$ share for the assessed range of these variables. Therefore, for especially low linear heat demand densities, individual heat supply is preferable. If a cheap supply of ULTDH is available, such as direct heat supply from excess heat, ULTDH could be feasible compared to LTDH for high plot ratios of 1 or higher and SH shares of 0.7 and higher. The economic feasibility of ULTDH suffered from additional investment- and fixed O\&M cost of the decentral units that were not outbalanced by the lower operation cost. Compared to LTDH, ULTDH benefits from reduced overall cost of decentral units, including, increase in COP, decrease in investment cost and optimization of installed capacity. The competitiveness of ULTDH systems is higher if the share of directly supplied energy is high, as the seasonal system COP increased with increasing SH share and plot ratio, i.e. increasing heat demand and less energy efficient buildings. This contradicts the development towards more energy efficient buildings with low space heating demand.

The higher seasonal system efficiency of ULTDH are not reflected in the economic feasibility of these systems. In order to become more competitive, future research should be directed towards reduction of cost of decentral units, including measures to improve the COP, reduction of investment cost and of $O \& M$ cost. Further, research is needed to answer whether the combination of district heating and cooling could help to increase the utilization of the central system structures and thereby decrease the specific cost.

\section{Acknowledgements}

This research project is financially funded by EUDP (Energy Technology Development and Demonstration) under the project "EnergyLab Nordhavn - New Urban Energy Infrastructures" (project number: 64014-0555). 


\section{Bibliography}

[1] Lund H, Werner S, Wiltshire R, Svendsen S, Thorsen JE, Hvelplund F, et al. 4th Generation District Heating $(4 \mathrm{GDH})$. Integrating smart thermal grids into future sustainable energy systems. Energy 2014;68:1-11. doi:10.1016/j.energy.2014.02.089.

[2] Yang $X$, Svendsen S. Ultra-low temperature district heating system with central heat pump and local boosters for low-heat-density area: Analyses on a real case in Denmark. Energy 2018;159:243-51. doi:10.1016/j.energy.2018.06.068.

[3] Elmegaard B, Schmidt Ommen T, Markussen M, Iversen J. Integration of space heating and hot water supply in low temperature district heating. Energy Build 2016;124:255-64. doi:10.1016/j.enbuild.2015.09.003.

[4] Ommen T, Thorsen JE, Markussen WB, Elmegaard B. Performance of ultra low temperature district heating systems with utility plant and booster heat pumps. Energy 2017;137:544-55. doi:10.1016/j.energy.2017.05.165.

[5] Reidhav C, Werner S. Profitability of sparse district heating. Appl Energy 2008;85:867-77. doi:10.1016/j.apenergy.2008.01.006.

[6] Ommen T, Markussen WB, Elmegaard B. Lowering district heating temperatures - Impact to system performance in current and future Danish energy scenarios. Energy 2016;94:273-91. doi:10.1016/j.energy.2015.10.063.

[7] Best I, Orozaliev J, Vajen K. Economic comparison of low-temperature and ultra-low-temperature district heating for new building developments with low heat demand densities in Germany. Int J Sustain Energy Plan Manag 2018;16:45-60. doi:10.5278/ijsepm.2018.16.4.

[8] Vivian J, Emmi G, Zarrella A, Jobard X, Pietruschka D, De Carli M. Evaluating the cost of heat for end users in ultra low temperature district heating networks with booster heat pumps. Energy 2018;153:788-800. doi:10.1016/j.energy.2018.04.081.

[9] Köfinger M, Basciotti D, Schmidt RR, Meissner E, Doczekal C, Giovannini A. Low temperature district heating in Austria: Energetic, ecologic and economic comparison of four case studies. Energy 2016;110:95-104. doi:10.1016/j.energy.2015.12.103.

[10] Lund R, Skaarup Østergaard D, Yang X, Vad Mathiesen B. Comparison of Low-temperature District Heating Concepts in a Long-Term Energy System Perspective. Int J Sustain Energy Plan Manag 2017;12:5-18. doi:dx.doi.org/10.5278/ijsepm.2017.12.2.

[11] Østergaard PA, Andersen AN. Booster heat pumps and central heat pumps in district heating. Appl Energy 2016;184:1374-88. doi:10.1016/j.apenergy.2016.02.144.

[12] Rambøll. District Heating Assessment Tool 2017. https://ens.dk/sites/ens.dk/files/Globalcooperation/dhat_report-10-17.pdf (accessed November 21, 2017).

[13] Caramaschi M, Østergaard KK, Christiansen $\mathrm{CH}$. Novel domestic hot water microbooster heat pump in ultra-low temperature district heating. 4th Int. Conf. Smart Energy Syst. 4th Gener. Dist. Heat., Aalborg, Denmark: 2018, p. 1-15.

[14] Caramaschi M, (MetroTherm). Personal communication 2019. 
[15] Mader G. Economic analysis of air-water heat pump technologies with a screening method (Doctoral thesis). Stockholm, Sweden: KTH Royal Institute of Technology, School of Industrial Engineering and Management; 2015.

[16] Bühler F, Petrović S, Holm FM, Karlsson K, Elmegaard B. Spatiotemporal and economic analysis of industrial excess heat as a resource for district heating. Energy 2018;151:715-28. doi:10.1016/j.energy.2018.03.059.

[17] By \& havn. Levantkaj 2018.

http://www.nordhavnen.dk/kvarterer+i+nordhavnen/indre+nordhavn/levantkaj.aspx (accessed February 6, 2019).

[18] European Commission. EU Regulation No. 626/2011 - Energy labelling of air conditioners. Off J Eur Union 2011;L 178:1-72.

[19] HOFOR. Projektforslag til Københavns Kommune - Fjernvarmeforsyning af Nordhavn 2013.

[20] Hansen CF, Hansen ML. Executive Order on the Publication of the Danish Building Regulations 2015 (BR15) 2015;2015.

[21] Wang PG, Scharling M, Wittchen KB, Kern-Hansen C. Technical Report 13-19 2001 - 2010 Danish Design Reference Year - Reference Climate Dataset for Technical Dimensioning in Building , Construction and other Sectors 2013.

[22] Danish Standards Association, European committee for standardization. Heat pumps with electrically driven compressors - Testing, performance rating and requirements for marking of domestic hot water units. EN 16147:2017, 2017.

[23] Aronsson S. Fjärrvärmekunders värme- och effektbehov (Heat and heat power demands from district heating customers). Göteborg, Sweden: Department of Building Services Engineering, Chalmers University of Technology; 1996.

[24] Frederiksen S, Werner S. District heating and cooling. Studentlitteratur; 2013.

[25] Persson U, Werner S. Heat distribution and the future competitiveness of district heating. Appl Energy 2011;88:568-76. doi:10.1016/j.apenergy.2010.09.020.

[26] Dansk Fjernvarme. Dansk Fjernvarmes statistik 20172018. http://www.danskfjernvarme.dk/viden-om/statistik-subsection/aarsstatistik/statistik-2017 (accessed June 20, 2018).

[27] Euroheat \& Power Board. Guidelines for District Heating Substations. Euroheat \& Power 2008:68.

[28] Jensen JK, Ommen T, Markussen WB, Elmegaard B. Design of serially connected district heating heat pumps utilising a geothermal heat source. Energy 2017;137:865-77. doi:10.1016/j.energy.2017.03.164.

[29] Thorsen JE, Ommen T. Field experience with ULTDH substation for multifamily building. Energy Procedia 2018;149:197-205. doi:10.1016/j.egypro.2018.08.184.

[30] Energistyrelsen. Vejledning i samfundsøkonomiske analyser på energiområdet 2018. https://ens.dk/sites/ens.dk/files/Analyser/vejledning_i_samfundsoekonomiske_analyser_paa_en ergiomraadet_-_juni_2018_v1.1.pdf (accessed July 22, 2019). 
[31] Danish Energy Agency. Finding your cheapest way to a low carbon future - The Danish Levelized Cost of Energy Calculator 2015.

https://ens.dk/sites/ens.dk/files/Globalcooperation/vejledning_Icoe_calculator.pdf.

[32] International Energy Agency, Agency, Nuclear energy agency. Projected costs of generating electricity 2015 Edition 2015.

[33] Danish Energy Agency, Energinet. Technology Data for Individual Heating Installations 2016:166. https://ens.dk/sites/ens.dk/files/Analyser/technology_data_catalogue_for_heating_installations -_marts_2018.pdf.

[34] Energinet.dk. Technology Data for Energy Plants 2016. www.ens.dk (accessed October 12, 2017).

[35] Energinet.dk. Technology Data for Energy Plants 2012.

https://ens.dk/sites/ens.dk/files/Analyser/technologydata_for_energy_plants__may_2012._updated_2015.pdf (accessed October 12, 2017).

[36] Pieper H, Ommen T, Bühler F, Paaske BL, Elmegaard B, Markussen WB. Allocation of investment costs for large-scale heat pumps supplying district heating. Energy Procedia 2017;147:358-67. doi:https://doi.org/10.1016/j.egypro.2018.07.104.

[37] Grosse R, Christopher B, Stefan W, Geyer R, Robbi S. Long term (2050) projections of technoeconomic performance of large-scale heating and cooling in the EU. Publ Off Eur Union 2017;EUR28859 E:1-180. doi:10.2760/24422.

[38] Zühlsdorf B, Meesenburg W, Ommen TS, Thorsen JE, Markussen WB, Elmegaard B. Improving the performance of booster heat pumps using zeotropic mixtures. Energy 2018;154:390-402. doi:10.1016/j.energy.2018.04.137.

[39] Metrotherm. Installatørprisliste 2018. 2018.

[40] Wolf S, Fahl U, Blesl M, Voss A, Jakobs R. Analyse des Potenzials von Industrie- wärmepumpen in Deutschland - Endbericht. 2014.

[41] Danish Energy Agency, ENERGINET. Technology Data for Energy Plants Generation of Electricity and District Heating 2016:1-186. doi:ISBN: 978-87-7844-940-5.

[42] Miara M. Ergebnisse zu neuen Feldmessungen von elektrisch angetriebenen Kompressionswärmepumpen. Tagung des Dtsch. Klima- und Kältetechnischen Vereins, Aachen: 2012, p. AA VI.2.

[43] HOFOR. EnergyLab Nordhavn Deliverable no. T5.4a: Optimizing temperatures in low-temperature district heating networks. 2019.

[44] Pellegrini $M$, Bianchini A. The innovative concept of cold district heating networks: A literature review. Energies 2018;11. doi:10.3390/en11010236. 
Highlights - Economic feasibility of ultra-low temperature district heating systems in newly built areas supplied by renewable energy

- Assessment of economic feasibility of ULTDH and LTDH for new developments

- Systematic assessment of boundary conditions on economic feasibility

- Additional investment and maintenance cost limit the feasibility of ULTDH

- Low temperature district heating is economically beneficial in the assessed cases

- Among the ULTDH variants house substations are beneficial for high plot ratios 


\section{Declaration of interests}

$\bigotimes$ The authors declare that they have no known competing financial interests or personal relationships that could have appeared to influence the work reported in this paper.

$\square$ The authors declare the following financial interests/personal relationships which may be considered as potential competing interests: 